\title{
Feasibility of lime and biopolymer treatment for soft clay improvement: a comparative and complementary approach
}

\author{
Hyginus Nwankwo Onah ${ }^{1} \cdot$ Donald Chimobi Nwonu ${ }^{1,2}$ (D) $\cdot$ Chijioke Christopher Ikeagwuani ${ }^{1,3}$
}

Received: 7 September 2021 / Accepted: 17 January 2022 / Published online: 8 February 2022

(c) The Author(s) 2022

\begin{abstract}
Highway pavement infrastructure projects which involve soil improvement should be executed, ensuring environmental sustainability. In the present study, guar gum (GG) and lime were assessed for the purpose of soft clay stabilization. The experimental program for the soil stabilization employed a two-stage process. The initial stage involves treatment of the soil with various percentages of lime $(3,5,7$, and $9 \%)$ and $\mathrm{GG}(0.6,1.0,1.4$, and $1.8 \%)$, maintaining the same material acquisition cost and considering curing $(0,7,14$, and 28 days) for the unconfined compressive strength (UCS). In the second experimental stage, a complementary approach in which $3 \%$ lime was combined with GG at various percentages $(0.1,0.2$, and $0.3 \%$ ) was employed. The tests conducted include UCS, California bearing ratio (CBR), and strength loss resistance (SLR). Results show that the sole use of lime and GG resulted in significant improvement in the UCS, albeit lime was better. While UCS improved with curing time for the lime-stabilized soil, UCS gain for GG occurred only for up to 7 days curing because biodegradation of GG by microbes in the soil ensues on further curing. Lime-GG stabilization resulted in better UCS and CBR improvement with curing than lime stabilization; however, lime stabilization yielded better SLR. The optimum additive content for strength improvement was obtained at $3 \%$ lime $+0.3 \%$ GG. Microstructural analysis indicated cementation in the stabilized soil. Predictive models for the UCS were developed based on regression methods. Model evaluation revealed that Gaussian process model provided the best UCS prediction.
\end{abstract}

Keywords Gaussian process regression $\cdot$ Guar gum $\cdot$ Lime $\cdot$ Microstructural analysis $\cdot$ Multiple regression analysis $\cdot$ Soil stabilization

Responsible Editor: Zeynal Abiddin Erguler

Donald Chimobi Nwonu

donald.nwonu@unn.edu.ng

Hyginus Nwankwo Onah

hyginus.onah@unn.edu.ng

Chijioke Christopher Ikeagwuani

chijioke.ikeagwuani@unn.edu.ng

1 Civil Engineering Department, University of Nigeria Nsukka, Nsukka 410001, Nigeria

2 School of Computing, Engineering and Physical Sciences, University of the West of Scotland, Paisley PA1 2BE, UK

3 African Center of Excellence for Sustainable Power and Energy Development, ACE-SPED, University of Nigeria Nsukka, Nsukka 410001, Nigeria

\section{Introduction}

Execution of highway infrastructure projects typically involves one form of earthwork or another. More often than not, the existing in situ soil material required for pavement or road embankment construction could be inept for application and termed weak. When the spatial existence of such soil deposit extends substantially both longitudinally and depth wise, it becomes imminent that one form of ground improvement is integrated into the overall project planning and execution. The major ground improvement techniques include mechanical and chemical stabilization (Ikeagwuani and Nwonu 2019; Soltani et al. 2018). The chemical method, however, sustains the improved strength of the soil for prolonged periods, making it more durable and apt (Ikeagwuani and Nwonu 2019). In this regard, the chemical soil improvement which utilizes additives blended with the soil to improve the physicochemical morphology primarily 
involves the use of either traditional (calcium-based) or nontraditional (non-calcium-based) additives.

Generally, cement and lime are the commonest traditional additives utilized for soil improvement. Their pre-eminence in the area of ground improvement cannot be over-emphasized. In a study by Chakraborty and Nair (2020), a weak soil was treated with various percentages of lime $(2,3$, and $8 \%$ ) and different curing ages up to 60 days. The unconfined compressive strength (UCS) was found to improve significantly with time exponentially. Moreover, due to the aptness of the lime treatment, under varying moisture-induced conditions, the UCS of the treated soil showed a linear increment with curing time. In another study, a high plasticity clay soil was treated with lime for use as road embankment material (Rosone et al. 2020). Results of the experimental program showed that a hyperbolic function best explicated the strength relationship due to lime treatment and curing. The strength improvement achieved was revealed to have resulted from reorientation of the pore structure due to bonding and formation of cementitious compounds within the soil matrix. Another study conducted by Eujine et al. (2017) resulted in significant improvement in UCS and California bearing ratio (CBR) of clay soils treated with lime and its derivate known as enzymatic lime. The outcome of the study considering maximum curing time clearly shows that an increment in UCS of about 30 to $45 \%$ was achieved with the additives for kaolin-treated clay, while the increment for bentonite-treated clay was approximately between 92 and $480 \%$. In the case of the CBR, the strength improved from 9 to $95 \%$ for the kaolin-treated clay, while the CBR of the bentonite-treated clay increased from 56 to $108 \%$. Similar outcomes have been reported elsewhere (Al-taie et al. 2016; Eujine et al. 2017; Kampala et al. 2020; Moghal et al. 2020). These studies clearly show the stabilization efficacy attainable with traditional additives, particularly lime stabilization.

In as much as the efficiency of traditional additives such as lime is undoubted, the environmental footprint associated with their production and usage is of great concern. Substantial quantities of $\mathrm{CO}_{2}$ emission, which is a greenhouse gas, are closely associated with the production/use of cement and lime (Chang et al. 2020; Nwonu 2021). Moreover, the undue increment in soil $\mathrm{pH}$ due to the $\mathrm{Ca}(\mathrm{OH})_{2}$ content of traditional additives promotes the solubility of heavy metal ions, contaminant mobility, and other undesirable leaching effects (Chang et al. 2020; Nwonu 2021).

These considerations have birthed the search and discovery of several alternative additives known as non-traditional stabilizers. Within this class, biopolymers have proved to be very promising in recent years due to eco-friendliness, availability, potential for high strength attainability, and similarity with traditional additives in field quality control (Chang et al. 2020). The different biopolymers, which have been employed for soft ground improvement, include xanthan gum, guar gum (GG), agar gum, gellan gum, starch, chitosan, and others (Bagriacik and Mahmutluoglu 2021; Chang et al. 2020; Smitha and Rangaswamy 2021; Sujatha et al. 2020; Vishweshwaran and Sujatha 2021). The most rampant of these, investigated in recent years for highway pavement fine-grained material stabilization, are the xanthan gum and GG (Fatehi et al. 2021). Due to the inherent ability of GG to hydrate rapidly under room and low temperatures to form very thick hydro-gels (Chang et al. 2020; Mudgil et al. 2014), it is a highly desirable biopolymer choice for soil stabilization. Moreover, the viscosity of GG solution clearly exceeds that of xanthan gum at the same concentration (Ayeldeen et al. 2017) and has a much lower carbon footprint (Fatehi et al. 2021).

Impressive leaps and bounds have been achieved in the area of soft soil stabilization using GG as an additive. In a recent study by Ayeldeen et al. (2017), xanthan gum and GG were both applied to improve a collapsible soil. It was discovered that GG exhibited better improvement in soil properties, including the shear strength and collapse potential. The soil cohesion was found to increase by about $147 \%$ from an initial value of $51 \mathrm{kPa}$, while the collapsible potential significantly dropped by about $80 \%$ from an initial value of $15.44 \%$ for dry mix method at $2 \%$ GG content. Further improvements were also recorded with 7-day curing. In another study, GG was employed at different percentages $(0.25,0.5,1.0$, and $1.5 \%)$ to stabilize two expansive soils denoted as GV and JP soils for use in construction of slopes (Acharya et al. 2017). The variation of the shear strength parameters (effective cohesion and effective friction angle) showed disparity in behavior at various GG contents. In the GV soil, the effective cohesion increased to attain a maximum value at $0.5 \% \mathrm{GG}$, after which a decline was reported, whereas the JP soil showed a steady increment of effective cohesion with GG addition, attaining peak value at $1.5 \%$ GG content. The effective friction angle showed a slight improvement at $0.25 \% \mathrm{GG}$, after which a gradual drop was recorded for the GV soil, while that of the JP soil failed to show any appreciable improvement with GG addition. Moreover, the optimum $0.5 \%$ GG dosage caused notable improvement in the 7-day UCS of the GV soil from 84.4 to $112.4 \mathrm{kPa}$ (33\% increment), while that of the JP soil similarly increased from 125.4 to $159.6 \mathrm{kPa}$ (27\% increment). These outcomes suggest that the effect of the various GG contents could be dependent on the soil plasticity and mineralogy, although the mineralogical composition of the two soils was not reported. In a related study by Sujatha and Saisree (2019), a highly compressible silty-clay soil was treated using GG at $0.5,1.0,1.5$, and $2.0 \%$ content. For all the soil properties investigated, including UCS, compression index, durability, swelling, and consolidation coefficient, the soil exhibited a gradual improvement with increase in GG content. Moreover, with increase in curing ages $(0,7,14$, 
28,56 , and 90 days), the UCS exhibited a gradual increment for all GG contents. Related studies have similarly reported varying outcomes with GG soil improvement technique at various additive contents (Chang et al. 2020; Fatehi et al. 2021; Mugada et al. 2017; Soldo et al. 2020). Hence, the past research efforts indicate that the extent of improvement expected or achievable with a preselected GG content for stabilization is case dependent and cannot be easily generalized. One thing common though is that at a predetermined optimum content, GG results in significant improvement of soil geotechnical properties.

Apparently, the adoption of GG for soft soil improvement is a viable option based on review of existing literatures. But as a result of the renowned use of traditional stabilizers in practice, it is crucial to directly compare and assess the practical advantages of utilizing GG over traditional lime stabilization or evaluate a complementary approach. Such direct comparisons have been rarely reported and are of utmost importance to transit from state-of-the-art to stateof-the-practice in the adoption of GG, which is a biopolymer stabilization method in field application.

This study thus investigated the strength improvement attainable with lime and GG acquired at the same cost for the stabilization of a soft clay soil. Moreover, the durability and time-dependent strength evolution are investigated through evaluation of the strength loss on soaking and various curing ages. This is very vital because GG is known to decompose into sugar and water by action of microorganisms, which are common in soil deposits. Furthermore, the untreated and treated soils were characterized microstructurally using scanning electron microscopy (SEM) and Fourier transform infrared spectroscopy (FTIR). Finally, the relationships between the additive content, curing time, and UCS were developed using regression-based methods, which include multiple linear regression (MLR), stepwise polynomial regression (SPR), and Gaussian process regression (GPR) techniques.

\section{Materials and test methods}

\section{Materials}

Natural soil The soil used for the present study is locally sourced clay, which is widely deposited in the study area. The soil was sampled at Hilltop area, Nsukka, very close to the University of Nigeria Nsukka using a disturbed sampling method. Thereafter, the soil was packed in air-tight bags and transported to the laboratory for testing. The sample collection point is located within the longitudes and latitudes corresponding to $7^{\circ} 24^{\prime} 50^{\prime \prime} \mathrm{N}$ and $6^{\circ} 51^{\prime} 25^{\prime \prime} \mathrm{E}$, respectively. The sampling area is a rapidly developing urban settlement,
Table 1 Geotechnical properties of the natural soil

\begin{tabular}{|c|c|c|c|}
\hline S/No & Property & & Description \\
\hline 1 & Specific gravity & & 2.65 \\
\hline 2 & Natural moisture content & & $14.1 \%$ \\
\hline 3 & Fines & & $73.2 \%$ \\
\hline 4 & Sand & & $26.0 \%$ \\
\hline 5 & Gravel & & $0.8 \%$ \\
\hline 5 & Liquid limit & & $36.5 \%$ \\
\hline 6 & Plastic limit & & $10.7 \%$ \\
\hline 7 & Plasticity index & & $25.8 \%$ \\
\hline 8 & $\mathrm{OMC}$ & & $19.8 \%$ \\
\hline 9 & MDD & & $1.73 \mathrm{~g} / \mathrm{cm}^{3}$ \\
\hline 10 & AASHTO classification & & A-6 \\
\hline 11 & USCS classification & & $\mathrm{CL}$ \\
\hline \multirow[t]{2}{*}{12} & CBR & Unsoaked & $11.9 \%$ \\
\hline & & Soaked & $10.5 \%$ \\
\hline 13 & UCS & & $76 \mathrm{kPa}$ \\
\hline 14 & SLR & & $84.6 \%$ \\
\hline
\end{tabular}

Table 2 Oxide composition of the natural soil and additives

\begin{tabular}{llcc}
\hline Compound (\%) & Soil & Lime & $\begin{array}{l}\text { GG (Sujatha and } \\
\text { Saisree 2019) }\end{array}$ \\
\hline $\mathrm{Al}_{2} \mathrm{O}_{3}$ & 32.6 & 15.0 & 0.5 \\
$\mathrm{SiO}_{2}$ & 62.8 & 5.3 & 1.6 \\
$\mathrm{Fe}_{2} \mathrm{O}_{3}$ & 2.9 & 0.1 & 10.2 \\
$\mathrm{CaO}$ & - & 60.0 & 16.3 \\
$\mathrm{~K}_{2} \mathrm{O}$ & 0.1 & - & 40.8 \\
$\mathrm{TiO}_{2}$ & 1.4 & - & - \\
$\mathrm{SO}_{3}$ & 0.3 & - & 7.03 \\
Loss on ignition & $<10$ & - & - \\
\hline
\end{tabular}

in which a great deal of construction is ongoing including infrastructure projects such as roads, embankment slopes, and building constructions on slopes. The in situ soil in the area is currently being replaced with more suitable materials, which has made construction costs within the study area prohibitive. Thus, it is believed that the outcome of the present study could provide further insight on the recommendation of an appropriate soil stabilization strategy.

Index properties and microstructural characterization of the natural soil were executed for proper soil identification. The index properties of the soil are summarized in Table 1, while the oxide composition is shown in Table 2. The particle size distribution is shown in Fig. 1. The soil is classified as clay of low plasticity and A-6 as per Unified Soil Classification and AASHTO systems, respectively, and suggests that the soil can be regarded to possess fair to poor rating as a pavement material (Murthy 2002). 
Fig. 1 Particle size distribution of the natural soil

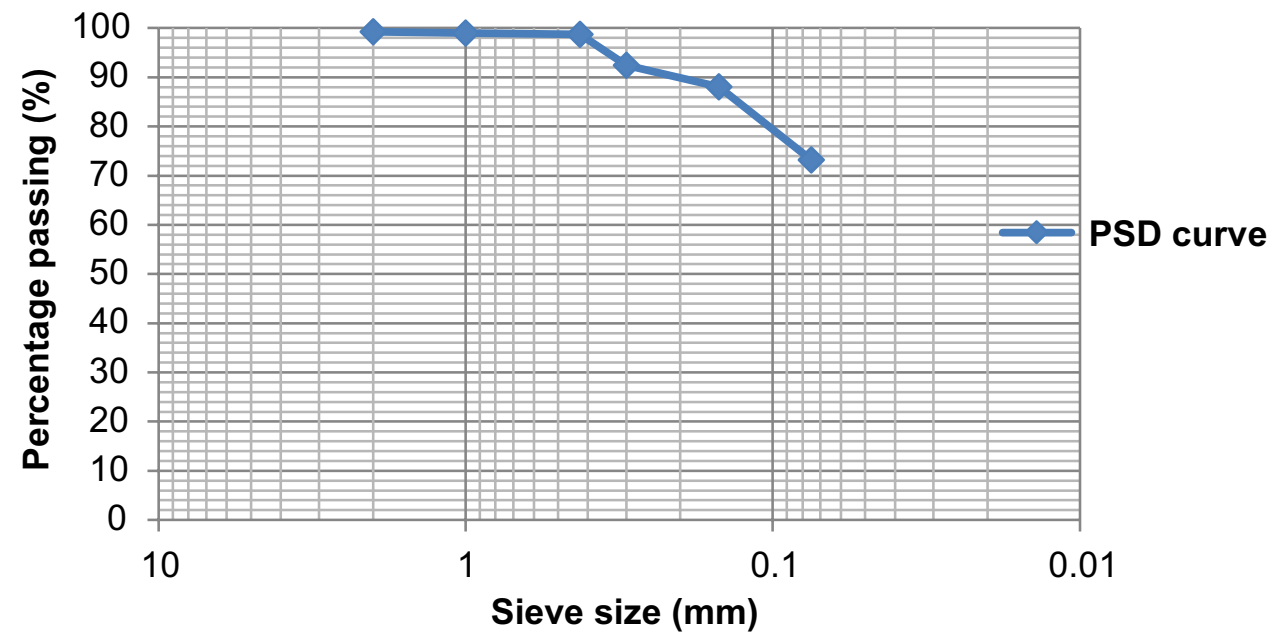

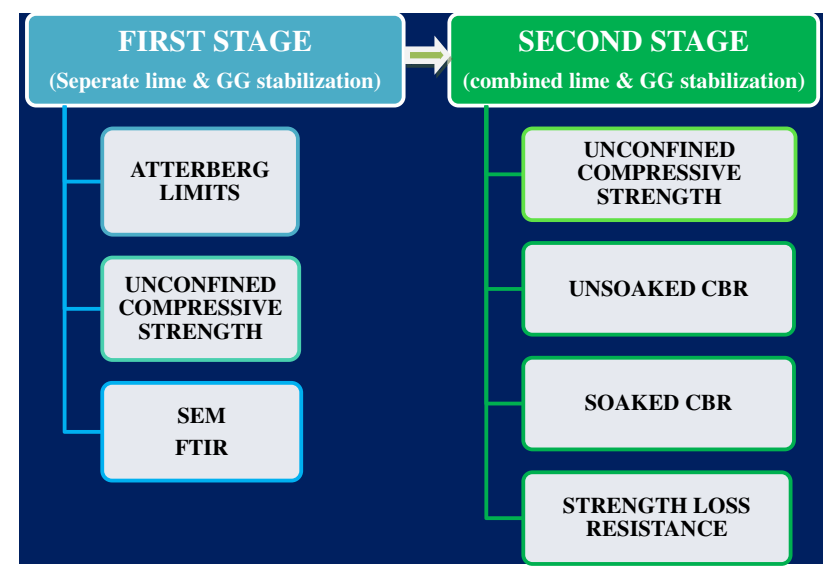

Fig. 2 Flow chart for the experimental program

Additives The chemical additives applied in the present study are hydrated lime and GG, which were purchased commercially and the location coordinates are given as $6^{\circ}$ $51^{\prime} 00^{\prime \prime} \mathrm{N}, 7^{\circ} 24^{\prime} 00^{\prime \prime} \mathrm{E}$. The lime was obtained at a cost of 5 $\$$ per kg, while $1 \mathrm{~kg}$ of the GG was purchased at $25 \$$ based on local exchange rates. Thus, using simple proportionality arithmetic, the equivalent quantities of (lime, GG) were obtained as $(3 \%, 0.6 \%),(5 \%, 1.0 \%),(7 \%, 1.4 \%)$, and $(9 \%$, $1.8 \%)$. Hence, the various percentages of lime used were $3,5,7$, and $9 \%$, while the quantities of GG used were 0.6 , $1.0,1.4$, and $1.8 \%$, all by dry weight of the soil. The oxide composition of the lime and GG is shown in Table 2.

\section{Methods}

\section{Experimental program}

A two-stage soil stabilization scheme was executed in the present study (Fig. 2). In the first stage, which was a comparative approach, the various individual percentages of lime
$(3,5,7$, and $9 \%)$ and GG $(0.6,1.0,1.4$, and $1.8 \%)$ were used to conduct Atterberg limits test and then, UCS was conducted at various curing ages $(0,7,14$, and 28 days). Microstructural analyses for various curing ages were also conducted. For the optimal lime- and GG-treated soil, SEM and FTIR were conducted for samples cured for 28 days. Additional tests including SEM and FTIR for 7 and 14 days curing were conducted for the optimal lime content, which exhibited strength gain with curing time.

Based on the inference from the strength test conducted in the first stage, the second stage of the testing was executed using a complementary approach in which an optimal lime percentage of $3 \%$ was combined with varying percentages of GG $(0.1,0.2$, and $0.3 \%)$. Lower GG contents were selected for the second stage based on cost consideration and noting that GG percentages beyond $0.6 \%$ are inapt for the stabilization process as inferred from the first experimental stage. The tests conducted in the second stage for samples compacted at their respective optimum moisture contents (OMC) include UCS considering various curing ages ( 0 , 7 , and 14 days), soaked and unsoaked CBR (0 and 7 days curing), and strength loss resistance (SLR). The mix ratios for the experimental program are summarized in Table 3.

\section{Laboratory tests}

The tests conducted in the laboratory for the natural and stabilized soils are briefly described as follows:

Atterberg limits In this study, the consistency limits of the soil, which include the liquid limit, plastic limits, and plasticity index, were gotten using the Casagrande's apparatus in accordance with British standard institute 1377 part 2 . The liquid limit is determined as the moisture content at which 25 blows of the Casagrande's cup close a specified groove made on the soil pat to about $13 \mathrm{~mm}$. The plastic limit was obtained as the moisture at which a $3-\mathrm{mm}$ rod formed by 
Table 3 Sample designations for the experimental program

\begin{tabular}{|c|c|c|c|c|}
\hline TEST & Specimen & Soil (\%) & Lime (\%) & Guar gum (\%) \\
\hline \multirow[t]{9}{*}{ Atterberg limits } & S0 & 100 & 0 & 0 \\
\hline & $\mathrm{S} 1$ & 97 & 3 & 0 \\
\hline & $\mathrm{S} 2$ & 95 & 5 & 0 \\
\hline & $\mathrm{S} 3$ & 93 & 7 & 0 \\
\hline & $\mathrm{S} 4$ & 91 & 9 & 0 \\
\hline & S5 & 99.4 & 0 & 0.6 \\
\hline & S6 & 99.0 & 0 & 1.0 \\
\hline & S7 & 98.6 & 0 & 1.4 \\
\hline & S8 & 98.2 & 0 & 1.8 \\
\hline \multirow{12}{*}{$\begin{array}{l}\text { Unconfined compressive strength, } \\
\text { soaked and unsoaked CBR }\end{array}$} & S9 & 100 & 0 & 0 \\
\hline & $\mathrm{S} 10$ & 97 & 3 & 0 \\
\hline & $\mathrm{S} 11$ & 95 & 5 & 0 \\
\hline & $\mathrm{S} 12$ & 93 & 7 & 0 \\
\hline & $\mathrm{S} 13$ & 91 & 9 & 0 \\
\hline & S14 & 99.4 & 0 & 0.6 \\
\hline & $\mathrm{S} 15$ & 99.0 & 0 & 1.0 \\
\hline & $\mathrm{S} 16$ & 98.6 & 0 & 1.4 \\
\hline & S17 & 98.2 & 0 & 1.8 \\
\hline & $\mathrm{S} 18$ & 96.9 & 3 & 0.1 \\
\hline & S19 & 96.8 & 3 & 0.2 \\
\hline & $\mathrm{S} 20$ & 96.9 & 3 & 0.3 \\
\hline \multirow[t]{5}{*}{ Strength loss resistance } & $\mathrm{S} 21$ & 100 & 0 & 0 \\
\hline & $\mathrm{S} 22$ & 97 & 3 & 0 \\
\hline & $\mathrm{S} 23$ & 96.9 & 3 & 0.1 \\
\hline & $\mathrm{S} 24$ & 96.8 & 3 & 0.2 \\
\hline & $\mathrm{S} 25$ & 96.7 & 3 & 0.3 \\
\hline
\end{tabular}

rolling exhibits shear cracks. The test was conducted for the lime-treated soil, after allowing a mellowing time of about $30 \mathrm{~min}$. In contrast, these tests could not be performed for the GG-treated soil because of gelling of the soil mass into a unitary semi-solid of homogenous nature, which cannot be sheared via grooving.

Compaction The moisture-density relationship of the soil samples was determined using the compactive energy of the British standard light. This involves the compaction of the soil in approximately three equal layers using 27 blows for each layer in the standard Proctor mold. Thereafter, the moisture contents and corresponding densities were measured to determine the OMC and maximum dry densities (MDD).

Unconfined compressive strength The compressive strength of the soil samples was obtained using the triaxial test apparatus capable of applying a load of about one-third the specimen height with the preclusion of minor principal stress application. The soil samples compacted at the required OMC were cured for the designated period in an atmosphere with humidity control. After curing, the extruded cylindrical specimens of about $38 \mathrm{~mm}$ by $76 \mathrm{~mm}$ height were carefully placed in the load frame of the triaxial machine. Uniform strain rates between 0.5 and $1 \% / \mathrm{min}$ were used for the test because the stiffened samples required less strain for failure, while the GG-treated soils failed at longer strains. The UCS was determined as the lesser of the compressive strength at maximum stress or the strength at $20 \%$ strain in accordance with the relevant British standard test method.

California bearing ratio The CBR of subgrade soils give an indication of its suitability and durability. Soaked and unsoaked CBR were determined for the natural and stabilized soils using the CBR machine. The samples were prepared via compaction at the required OMC and energy in a standard CBR mold, after which curing was done. Thereafter, the test samples were gently placed in the load frame of the CBR machine for the unsoaked samples. In the case of the soaked CBR, the samples were further soaked in water for 4-day period before testing. The load was applied at a uniform rate of $1.2 \mathrm{~mm} / \mathrm{min}$, after which load-penetration curves were plotted for the CBR determination in accordance with the relevant British standard test method. 
Strength loss resistance The SLR in this study was determined using the wax curing-soaking test as per previous studies (Etim et al. 2017; Nwonu and Ikeagwuani 2021a). In this test, two specimens were prepared for each soil sample based on the aforementioned compaction method for the UCS test. Then, one of the specimens is waxed top and bottom and allowed to cure for 7-day period, after which it is de-waxed and soaked in water for 4 days before testing. The other specimen is waxed at the top and bottom and allowed to cure for 14 days, after which it is de-waxed and tested. The UCS of both specimens is then determined and the SLR is computed as the percentage ratio of the soaked specimen to that of the unsoaked specimen.

Microstructural analysis The micro-level changes in the stabilized soil were verified using SEM and FTIR. The clay mineral of the natural soil was characterized using the XRD method and the oxide compositions of the natural soil and the additives were determined using X-ray fluorescence (XRF). The SEM was conducted on gold-coated samples in the Phenom ProX machine; the FTIR was determined based on absorbance for wavenumbers between 600 and $4000 \mathrm{~cm}^{-1}$ using Agilent technologies; the XRF was determined using ARL-XRF Advantx1200 model; and finally, the Phillip Goniometer was used for the XRD test. The detailed test methods are summarized in previous studies (Agunwamba et al. 2021; Ikeagwuani et al. 2019; Nwonu and Ikeagwuani 2021a, b).

\section{Predictive modeling}

In order to derive meaningful relationships to predict the strength behavior of stabilized soils, predictive modeling is pertinent. In this study, simple regression methods, which are based on ordinary least squares, and an advanced regression technique, which is based on Gaussian process, were employed for the UCS prediction, considering additive content (A) and curing period (T) for the UCS of both lime- and GG-stabilized soils. The choice of these supervised prediction models is rationally made based on reported recommendation for geotechnical application (Jong et al. 2021) and is further explicated in the ensuing sections. The summary of the steps required for each of these methods is provided thus:

\section{Multiple regression analysis}

The multiple regression methods used for the predictive modeling are the multiple linear regression (MLR) and the stepwise polynomial regression (SPR). The choice of the MLR and SPR methods is because if the underlying relationship is linear, they are more plausible for practical application and are able to give explicit model equations. Moreover, SPR can be able to represent non-linear polynomial relationships. A simple case of the OLS criterion is presented to briefly introduce the concept of the multiple regression analysis. Consider a predictor, $x_{i}$, and its outcome variable, $y_{i}$, with their true mean estimators $\zeta_{0}$ and $\zeta_{1}$ for a given data as shown in Eq. 1.

$y_{i}=\zeta_{0}+\zeta_{1} x_{i}+\varepsilon_{i}$

where $\varepsilon_{i}$ is the random error involved in the statistical model.

The OLS procedure seeks the best estimators of $\zeta_{0}$ and $\zeta_{1}$, denoted as $\hat{\zeta}_{0}$ and $\hat{\zeta}_{1}$, which minimizes the error in form of the squared deviations of the actual outcome variable $y_{i}$ and its estimated equivalence $\hat{y_{i}}$, known as the residual sum of squares (RSS). The expression is as shown in Eq. 2.

$R S S=\sum_{i=1}^{m}\left(y_{i}-\hat{y}_{i}\right)^{2}$

Through the minimum point evaluation using differential calculus and solving the resulting system of linear equations, the best estimators $\widehat{\zeta}_{1}$ and $\hat{\zeta}_{0}$ are expressed as shown in Eqs. 3 and 4 , respectively.

$\widehat{\zeta_{1}}=\frac{\sum x_{i} y_{i}-\frac{1}{m}\left(\sum x_{i} \sum y_{i}\right)}{\sum x_{i}^{2}-\frac{1}{m}\left(\sum x_{i}\right)^{2}}$

$\widehat{\zeta_{0}}=\overline{y_{i}}-\widehat{\zeta_{1}} \overline{x_{i}}$

where the respective $\overline{y_{i}}$ and $\overline{x_{i}}$ denote the mean of the outcome and predictor variable.

The solution of a multiple regression problem requires the extension of the OLS procedure for an array of data, which consists of a set of $n$ predictors with $n+1$ estimators defining the relationship between the outcome variable $y_{i}$ and the $n$ predictor variables. These $n+1$ estimators are similarly found such that the RSS expressed in Eq. 5 is minimized. The solution of the set of the resulting system of linear equations can easily be expressed in matrix form, which makes the computation of the $n+1$ estimators expedient.

$R S S=\sum\left(y_{i}-\hat{\zeta}_{0}-\hat{\zeta}_{1} x_{i 1}-\hat{\zeta}_{2} x_{i 2}-\cdots-\hat{\zeta}_{n} x_{i n}\right)^{2}$

In the SPR method, only the second-order model and interaction were considered to keep the predictive model relatively simple. Moreover, in executing the stepwise analysis, the $\alpha$ value used is 0.15 . The entire analysis was executed using Minitab.

\section{Gaussian process regression}

The Gaussian process regression (GPR), which is a less parametric supervised learning technique as applied in this study, simply employs the Gaussian process (GP) as an 
extension of the Gaussian distribution to generate a multidimensional subset. This subset is such that each obeys the multivariate Gaussian distribution (Ebden 2008). The GPR is specially advantaged because it is a non-parametric, probabilistic method based on kernels, which does not depend on underlying parametric assumptions and can give insight into the presence of non-linearity in the data, and hence, was chosen for the present study. The basic assumption in the GPR is that the covariance function principally relates one observation to the other since the mean of each nearest neighboring GP is taken to be zero. A suitable covariance function of the squared exponential is introduced in Eq. 6 (Ebden 2008; Sivia and Skilling 2006).

$\vartheta\left(z, z^{\prime}\right)=\sigma_{f}^{2} e^{\left[\frac{-\left(z-z^{\prime}\right)^{2}}{2 k^{2}}\right]}$

where $\vartheta\left(z, z^{\prime}\right)$ is the covariance function of $f(z), \sigma_{f}^{2}$ is the maximum permissible covariance, and $k$ is the length parameter.

Each observation $y$ in the dataset can be represented as a Gaussian noise model as shown in Eq. 7. Then, the noise can simply be integrated into the covariance as shown in Eq. 8, wherein $\sigma_{n}^{2}$ is the counterpart of $\sigma_{f}^{2}$ in the noise model.

$y=f(z)+N\left(0, \sigma_{n}^{2}\right)$

$\vartheta\left(z, z^{\prime}\right)=\sigma_{f}^{2} e\left[\frac{-\left(z-z^{\prime}\right)^{2}}{2 k^{2}}\right]+\sigma_{n}^{2} \delta\left(z, z^{\prime}\right)$

The GPR requires the explicit computation of the covariance in Eq. 8, which can be summarized as the matrices $Z$, $Z^{*}$, and $Z^{* *}$. Based on the definition of the GP, the testing set which is the unknown $y^{*}$ is estimated given the training set as a conditional probability. Representing the data as a subset of a multivariate Gaussian distribution, it follows that:

$\left[\begin{array}{c}y \\ y *\end{array}\right] \sim N\left(0,\left[\begin{array}{cc}Z & Z_{*}^{T} \\ Z * Z * *\end{array}\right]\right)$

The required conditional probability $\left(y_{*} \mid y\right)$, given the training set $y$, which follows the Gaussian normal distribution, is expressed as shown in Eq. 10. The mean of this distribution (Eq. 11) is the predicted response outcome, which is our interest.

$y_{*} \mid y \sim N\left(Z_{*} Z^{-1} y, Z_{* *}-Z_{*} Z^{-1} Z_{*}^{T}\right)$

$\bar{y}=K_{*} K^{-1} y$

The outlined procedure above can be extended to multiple predictors by considering $z$ as a vector and substituting the zero vector in (9) with some $f(z)$ (Rasmussen and Williams 2006). The GPR was implemented using MATLAB and a parametric approach was employed for initialization of the hyper-parameters, which are the covariance function parameters $\left[k, \sigma_{f}, \sigma_{n}\right]$, and that of the likelihood function. In all the predictive models (MLR, SPR, and GPR), $65 \%$ of the entire dataset was used for fitting, while the remainder was used for validation. Outliers in the predictions of the validation data for all the models were pruned to avoid spurious solutions. Model aptness was evaluated on the validation dataset using the following statistical indices: coefficient of determination $\left(R^{2}\right)$, root mean square error (RMSE), and mean absolute percentage error (MAPE). The computations are well detailed (Ikeagwuani and Nwonu 2021).

\section{Results and discussion}

\section{Index properties}

The result of the Atterberg limits for the lime-stabilized soil is summarized in Table 4, while the moisture-density relationships for the OMC and MDD of the stabilized soils are shown in Fig. 3. The addition of lime to the soil caused a steady drop in the plasticity index of the soil. Typically, the hydration of lime causes an initial stiffening effect on the soil due to cation exchange process, which occurs at the diffuse double layer (DDL) of clay soils. The $\mathrm{Ca}^{2+}$ ions from the aqueous solution of the lime, which are liberated on hydration, quickly displace weakly held hydrous ions at the DDL with a gradual formation of cementing compounds. Further increment of the lime content resulted in a gradual formation of cementing compounds within the soil matrix. As a result, the cemented soil is unable to further adsorb water onto the DDL, which has already been stabilized as a result of cation exchange process and hence, the plasticity of the stabilized soil is greatly reduced. Similar outcomes have been reported with lime stabilization (Ikeagwuani,et al. 2019; Nwonu and Ikeagwuani 2021a).

The variation of the moisture-density relationship for the stabilized soils lucidly indicates the additives effect on the

Table 4 Atterberg limit of the lime-stabilized soil

\begin{tabular}{llll}
\hline $\begin{array}{l}\text { Lime con- } \\
\text { tent }(\%)\end{array}$ & Liquid limit (\%) & Plastic limit (\%) & $\begin{array}{l}\text { Plasticity } \\
\text { index }(\%)\end{array}$ \\
\hline 0 & 36.5 & 10.7 & 25.8 \\
3 & 44.4 & 24.8 & 19.6 \\
5 & 42.8 & 23.1 & 19.7 \\
7 & 39 & 21.1 & 17.9 \\
9 & 43 & 36.4 & 6.6 \\
\hline
\end{tabular}


Fig. 3 Moisture-density curves for (a) lime- and (b) GG-stabilized soils

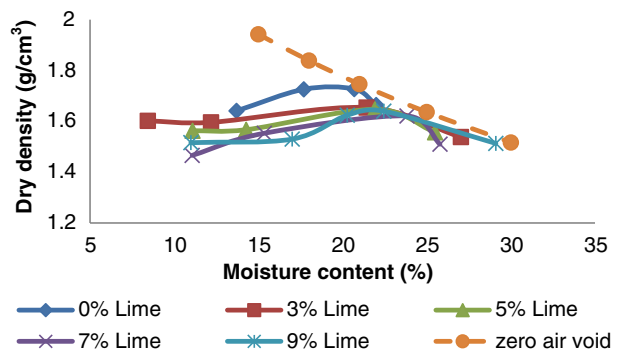

(a)

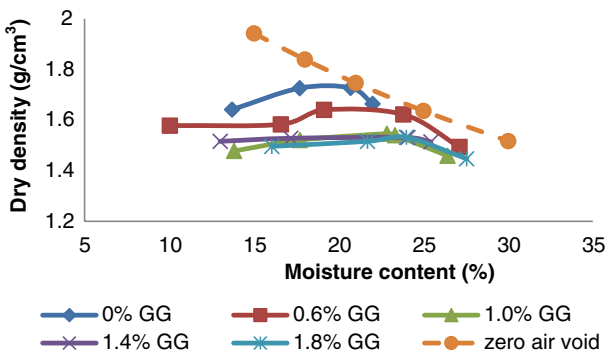

(b) soil. The gradual increment of the OMC with increase in additive content depicts higher moisture demand for chemical reactions. Lime hydrates, absorbing more water for the release of cations, which reacts with the soil to induce changes in the soil structure (Fig. 3a). In a similar way, GG rapidly absorbs moisture for the formation of binding gels through the process of hydroxylation, which resulted in the noted increase in OMC (Fig. 3b). The reverse was the case with the MDD, where a drop in the soil MDD was observed with increase in additive content. The trend can be attributed to softening effect of the biopolymer gels that encourages clumping of the clay particles, which makes compaction less efficient, thereby leaving behind voids in the soil matrix. This softening prevails because the rate of crystallization of biopolymer hydro-gels is time-dependent (Ayeldeen et al. 2017; Fatehi et al. 2021) and the preclusion of compaction delay makes a premature hydro-gel crystallization condition to subsist. In the case of lime stabilization, the initial strength gain that causes a stiffening effect on the soil particles also renders them less amenable to effective remolding during compaction with the consequent prevalence of voids. This can be evidenced in the trend of the compaction curves, which plotted below the zero air void line for the lime-stabilized soil and gradually shifted towards the right and below that of the natural soil (Fig. 3a). In comparison with the lime stabilization, the GG resulted in lower MDD because of its tendency to swell on moisture absorption, and the transformation of the soil into a semi-solid state, which inhibits the effective compaction and void expulsion. However, the plot of the compaction curves below the zero air void line for the GG-stabilized soil was similar to that for the lime stabilization (Fig. 3b).

\section{Unconfined compressive strength}

The trends of the UCS variation with additive content and curing age are represented in the charts of Figs. 4 and 5, respectively, for lime and GG. Clearly, the UCS of the soil progressively increased with addition of lime. In addition, higher strength gain was achieved with curing age. The maximum UCS of $587.5 \mathrm{kPa}$, attained for 3\% lime after 28-day curing, represents a notable increment of about $670 \%$ in the
UCS which shows the effectiveness of lime stabilization. This tremendous increment in the UCS is connected with the

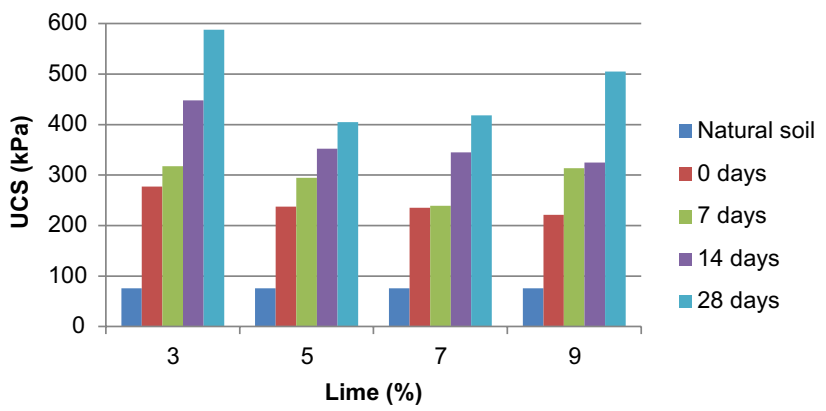

Fig. 4 UCS of lime-stabilized soil at various curing ages

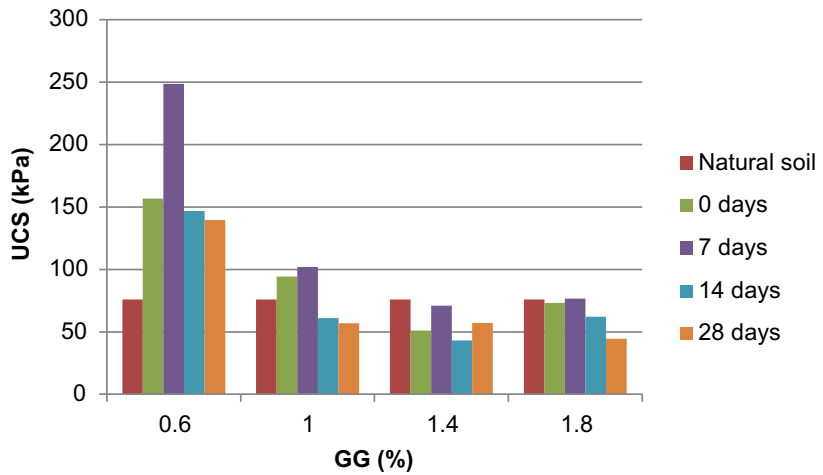

Fig. 5 UCS of GG-stabilized soil at various curing ages

initial and long-term strength gain on addition of lime. At $3 \%$ additive content, the soil rapidly stiffened and yielded the significant strength gains and imparted a brittle stress-strain response wherein very high compressive loads were sustained at very low strains. The strength gain progressed with curing due to the occurrence of chemical pozzolanic reaction occasioned by the presence of alumina-silicate in the soil and calcium oxide $(\mathrm{CaO})$ from the lime (Table 2$)$ that ultimately led to the formation of cementitious compounds with time. 
However, it has to be noted that on further increment of lime content, the soil became more brittle and began to exhibit micro-cracks, which caused a notable drop in strength as can be observed for the 5\% lime content. The cracks gradually disappeared with curing effect due to the formation of cementitious compounds and explicate the gradual increase in UCS with curing time. Moreover, with further lime addition (7-9\%), initial strength dropped due to brittle crack formations but rapidly increased with curing due to higher formation of cementitious compounds resulting from higher supply of $\mathrm{CaO}$ for chemical reaction. It can be inferred from the UCS trend that the optimal lime content is $3 \%$ lime based on crucial quality attributes of effectiveness and economy.

In contrast to the trend of UCS for lime stabilization, the GG-treated soils exhibited an initial strength gain, which was peaked at $0.6 \% \mathrm{GG}$, after which the UCS significantly dropped. In addition, strength improvement was achieved with only 7-day curing period, beyond which strength attenuation resulted. The initial strength gain can be adduced to the formation of biopolymeric binding gels within the soil matrix, which increases the inter-particles bond between silica and alumina clay mineral sheets, thereby reducing the interaction of water at the DDL of the soil. This action encouraged stability at the DDL due to the hydroxylation process of the GG that increases its molecular weight and viscosity with the resultant proliferation of the prevalence of adequate hydrogen bonds within the soil-GG matrix, which caused the strength gain. As a result, the soil UCS significantly increased to a peak value of about $250 \mathrm{kPa}$, which represents a strength gain of about $230 \%$.

However, excess quantity of the GG induces an adverse softening effect on the soil grains, which makes the soil to behave like a rubberized semi-solid during crystallization. This softening effect is connected with the insufficient rate of crystallization of the biopolymeric chains by way of inadequate crosslinking prevailing in soil-GG matrices with higher GG contents. This is plausible because the higher GG contents, which attract more hydroxyl groups, are highly viscous, and could require additional time to adequately dehydrate, crosslink, and produce a denser soil matrix during crystallization (Ayeldeen et al. 2017; Fatehi et al. 2021; Sujatha and Saisree 2019). Similar decline in strength has been reported previously (Acharya, et al. 2017; Fatehi et al. 2021).

Furthermore, the drop in UCS with curing beyond 7 days can be explained from the biodegradation effect of the GG biopolymer. It has been reported that GG can degrade on the action of enzyme or microbes to simple sugar and water (Mudgil et al. 2014). The consequent effect is that the hydrogen bonding initially provided by the GG weakens, in addition to the exposure of clay particles to moisture ingress. This is a plausible reason because clay soils contain microbes, which can act on GG to induce such degradation effects. The use of GG beyond $0.6 \%$ is regarded inefficient and has no engineering benefit in terms of strength improvement and economy. Thus, $0.6 \%$ GG content can be taken as the maximum threshold additive content for substantial strength gain.

\section{Lime hydro-gel stabilization}

\section{Unconfined compressive strength}

Adopting a complementary approach of combining 3\% lime and various percentages of GG $(0,0.1,0.2$, and $0.3 \%)$ produced the result shown in Fig. 6 . The compressive strength of the soil gradually increased with the addition of GG and curing time as well. The hydration of lime, which caused the stiffening of the soil particles, makes the soil capable of withstanding high stress under low strain. However, the combination of lime and GG results in a soil-additives matrix with a more desirable stress-strain response in which the soil is able to resist higher compressive stress and axial strain, imparting residual strength to the soil beyond the peak failure. The initially pronounced peakbrittle fracture typical in the stress-strain response for lime stabilization wanes in the case of lime-GG stabilization due to a self-healing mechanism introduced by crosslinked GG hydro-gels. The positive improvement observed in the soil UCS behavior is adduced to the complementary action of the lime and hydro-gels formed in the soil that resulted in about $26 \%$ maximum increment (that is, from 277.3 to $349 \mathrm{kPa}$ ) in the UCS of the $3 \%$ lime-stabilized soil at $3 \%$ lime $+0.3 \%$ GG.

This reported improvement in the soil UCS can be explicated based on the complementary positive effects of the additives. In the presence of moisture, the soil stiffens on lime hydration. Then, the resulting micro-pores are aptly cemented by the thick, continuous bio-films formed by the hydroxylation of the GG to form viscous biopolymeric chains. Furthermore, with time, cementitious lime compounds (calcium silicate hydrates and calcium aluminates hydrates), as well as more hydroxyl functional groups added to the soil matrix, which forms hydro-gels, yield additional strength gain. These changes improved the strength gain with curing time and maximum percentage improvements of about $25 \%$ and $35 \%$ for 7 and 14 days curing were respectively achieved with $3 \%$ lime $+0.3 \%$ GG. Moreover, during curing, the hydro-gels are able to dehydrate and crystallize more rapidly because of the moisture demand of the lime pozzolanic reaction. Consequently, improper particle clumping (aggregation) is precluded and the formation of adequately crosslinked bio-cements that hold the soil particles in a highly adhesive and densely 
Fig. 6 UCS of lime-GG-stabilized soil at various curing ages

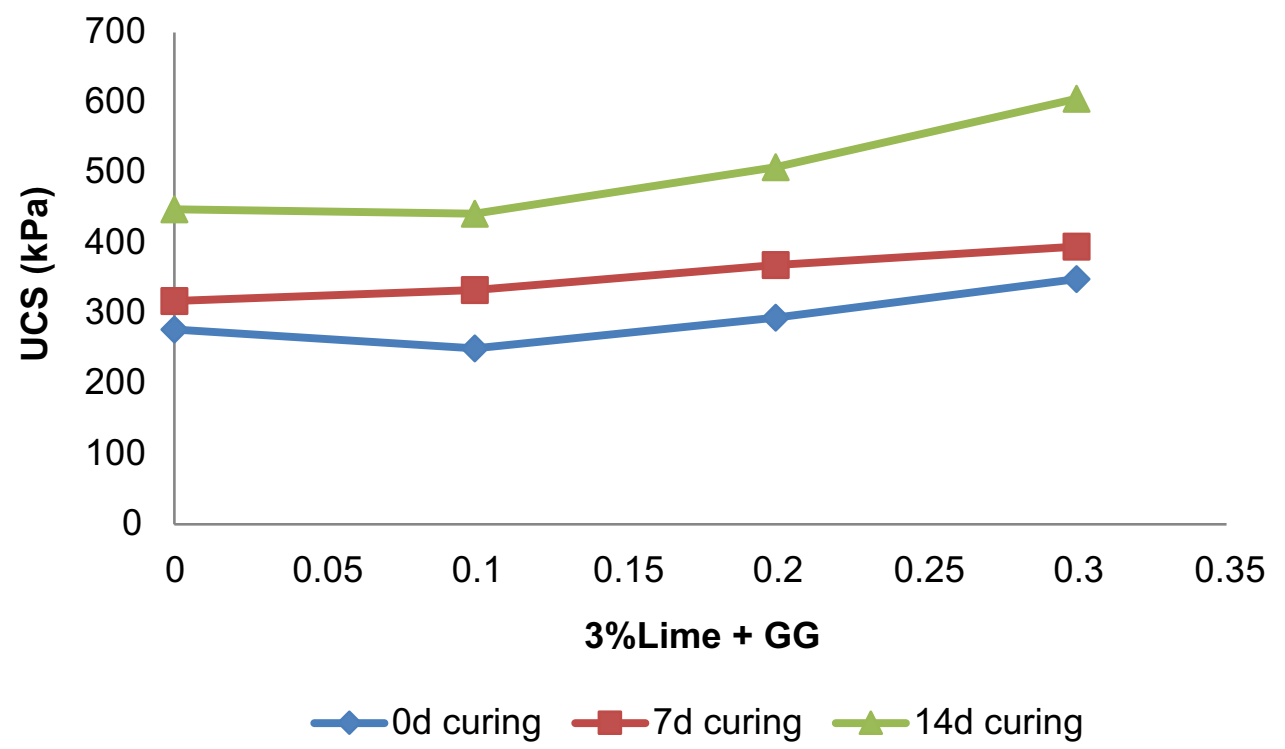

aggregated morphology results (Chen et al. 2013; Sujatha and Saisree 2019).

In contrast to the GG-stabilized soils, the lime-GGstabilized soil exhibited strength improvement with curing time. The UCS of the lime-GG-stabilized soil progressively increased with curing time beyond 7 days and the reason for this can be explicated. Unlike the GG-treated soils, the limeGG-stabilized soil causes an alkaline environment to exist within the soil matrix due to the presence of lime. The implication of this is that the microbes present in the soil, which are posited to be responsible for the biodegradation of the $\mathrm{GG}$, are likely to be acidophilic in nature. This implies that they can only thrive in acidic environments and the alkaline medium provided by the lime-GG stabilization inactivates them and they are unable to break down the biopolymeric bonds formed by the GG, which further contributed to the strength gain. Hence, strength gain was sustained with curing time in the lime-GG-stabilized soils.

\section{California bearing ratio}

The ability of the stabilized soil to be utilized as a highway pavement material is depicted by the CBR shown in Figs. 7 and 8 for unsoaked and soaked conditions, respectively. In the unsoaked condition, the natural soil with a CBR of $11.6 \%$ modestly satisfies the subgrade requirement as per the relevant standard (Nigerian General Specification 1997), which stipulates a minimum value of $10 \%$. However, the subbase requirement of $30 \%$ makes the natural soil inadequate for such application. Furthermore, the $3 \%$
Fig. 7 Unsoaked CBR of limeGG-stabilized soil at various curing ages

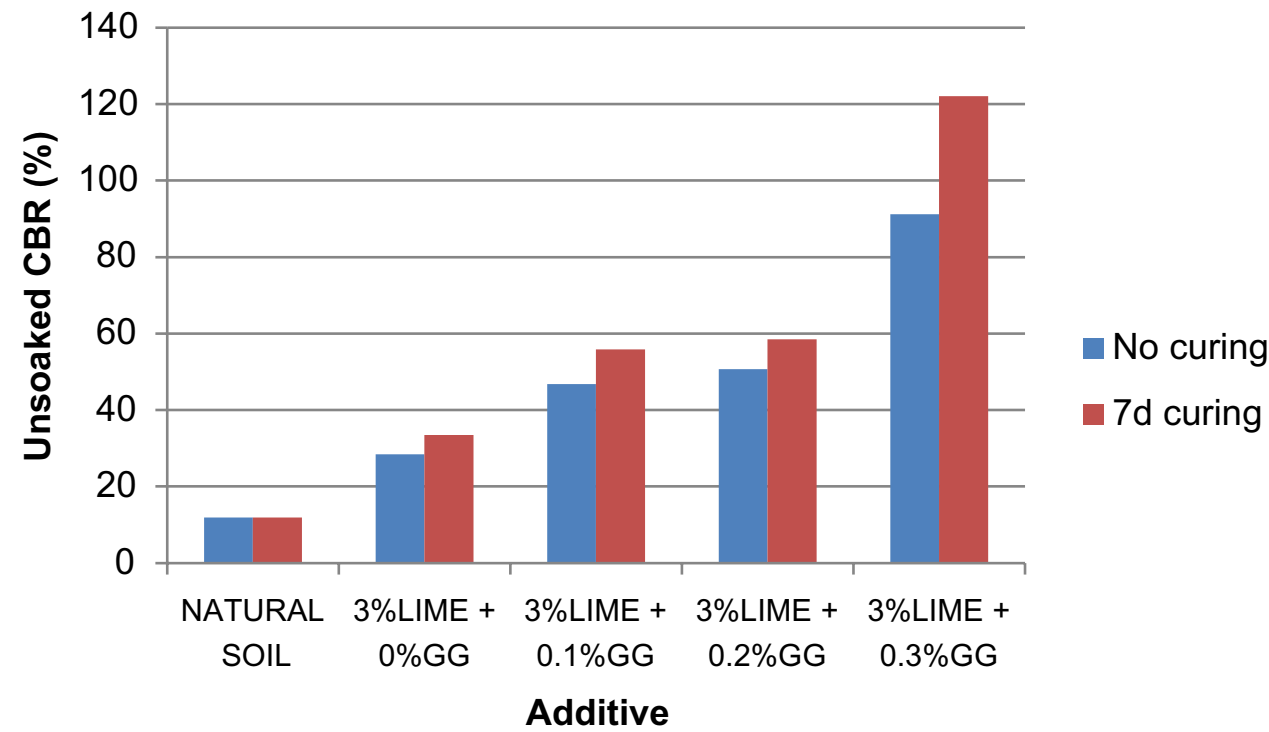


Fig. 8 Soaked CBR of limeGG-stabilized soil at various curing ages

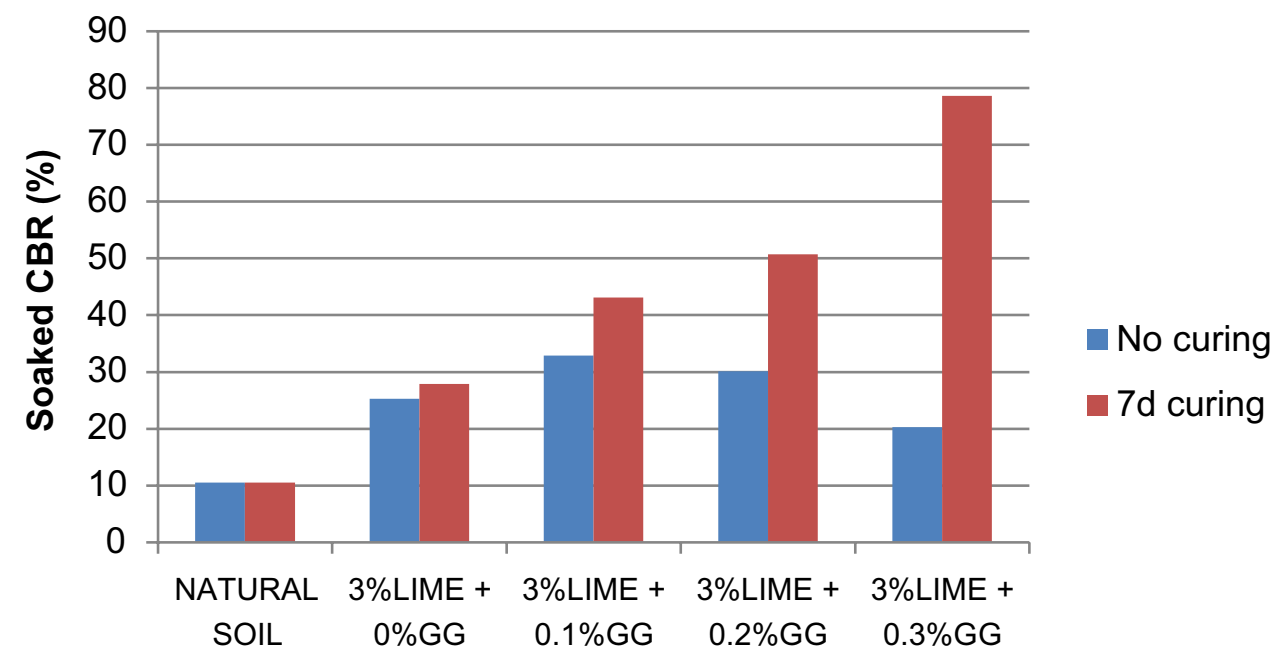

Additive lime-stabilized soil provides further improvement in the subgrade capability of the soil, but is still found wanting as a subbase material.

In contrast, the lime hydro-gel treatment improves the soil significantly to satisfy the subbase requirement, with or without curing. Also, the cured stabilized soil samples attained higher bearing strength. The improved ability of the lime-GG-treated soil is attributed to the formation of cementitious compounds and hydro-gels. The brittle behavior induced by lime stabilization produces discrete cemented soil particles, which are held together in cohesion and resist crushing via particle thixotropy property.

However, it has to be noted that the overall cohesive strength due to lime stabilization is attenuated by brittle micro-cracks formation. These micro-cracks in the case of lime-GG stabilization are expediently filled by way of continuous layers of bio-films formed by the hydroxylated viscous GG that accumulates and further provides improved bonding within the soil-additives matrix (Ayeldeen et al. 2017). This ultimately creates a bridging effect when glassy phases are formed on dehydration with time (Sujatha and Saisree 2019; Viswanath et al. 2017), which efficiently resists the penetrative load from the CBR plunger. Clearly, higher GG content and curing result in better hydrogel bonding and bioaccumulation within the soil voids and therefore, the stabilized soil matrix aptly acts as a unitary, idealized rigid mass, capable of effective load transfer and resistance.

In the case of the soaked CBR, the values increased for the stabilized soil to achieve the maximum of $32.9 \%$ at $3 \%$ lime $+0.1 \% \mathrm{GG}$ content for the uncured specimen. Further increment in the GG content caused a decline in CBR. In contrast, the CBR prosaically increased in the 7-day cured specimens. The drop observed in the uncured specimens is adduced to the weakening and improper formation of the hydrogen bonds during the soaking. This is because with increase in the addition of $\mathrm{GG}$, the soil-additives matrix requires additional time for the completion of the hydro-gel crystallization as earlier highlighted. Noting that the uncured specimens could not adequately crystallize, the prevailing bonds were weak and quickly degraded due to soaking. Conversely, the cured specimens were able to dehydrate due to curing and thus, achieved adequate crystallization with consequent strength increment.

\section{Durability}

The outcome of the SLR based on the wax curing-soaking test is shown in Fig. 9. It can be deduced that the natural soil exhibited the maximum SLR in comparison with the stabilized soils. Furthermore, the lime-stabilized soil achieved higher SLR when compared with soil specimens admixed with lime and GG. The natural soil was found to satisfy the threshold of $80 \%$ specified as the minimum SLR (Etim et al. 2017; Nwonu and Ikeagwuani 2021a). However, the stabilized soils fell short of the stipulated SLR. This suggests that the stabilized soils may have a shorter life span and may be unable to maintain the strength improvement over a prolonged time period, considering adverse environmental conditions such as wetting and drying in situ. Instructively, the lime-GG-stabilized soils exhibited lower SLR and can be regarded to be less durable in comparison with the lime-stabilized soil. This outcome can be largely attributed to the weakening effect caused by soaking. During the soaking period, the GG particles absorb moisture continuously to swell adversely, which precludes the dehydration and crystallization of the GG hydro-gels to form the required fiber crosslinks. As a result of this swelling effect, the initial strength gain imparted 
Fig. 9 SLR of lime-GG-stabilized soil

to the soil by lime is partly lost and this explains why the lime-stabilized soil exhibited higher SLR than the limeGG-stabilized soil. The implication of the results obtained is that further studies could explore admixtures that may improve or complement the durability potential of GG as a veritable soil stabilization agent.

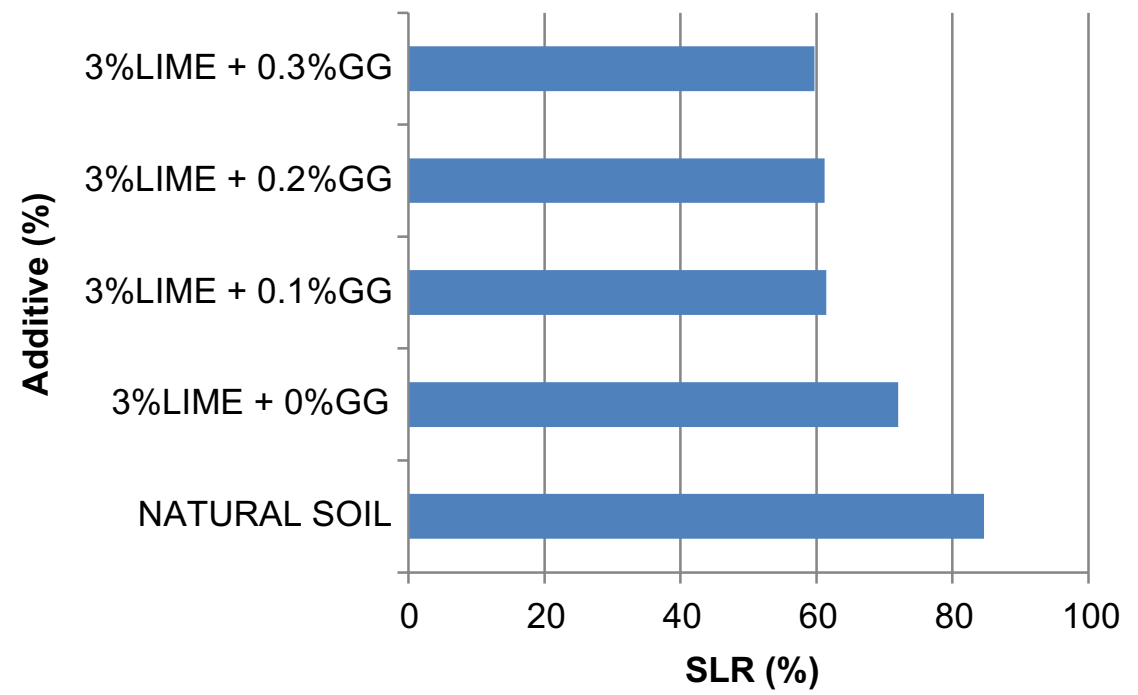

SLR

\section{Microstructural stabilization framework}

\section{Natural soil and additives}

In order to identify the natural soil as clay, the XRD pattern of the soil, shown in Fig. 10, was evaluated. Clearly,

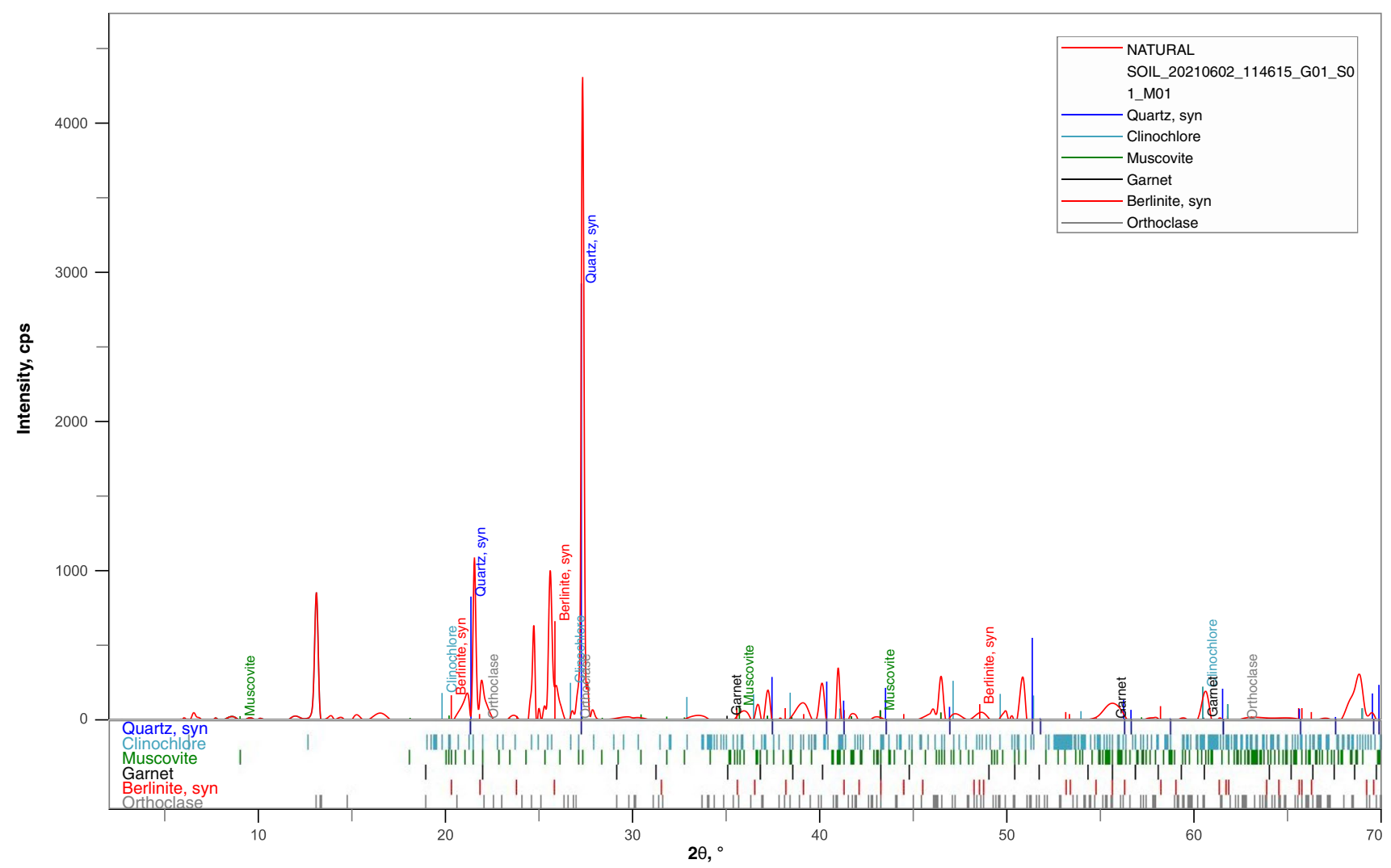

Fig. 10 XRD pattern of the natural soil 
the peaks show the presence of various minerals, which include quartz, clinochlore, muscovite, garnet, berlinite, and orthoclase. Most of these minerals are rock-forming minerals and as such, suitably represent the parent rock materials from which clay soils are formed (Mackenzie 1975). Two of the minerals, muscovite and clinochlore, can be associated with clay mineral groups. Muscovite belongs to the class of the dioctahedral micas, which are designated as 2:1 type clay minerals (Bleam 2017). The inherent isomorphous substitution in the mica group is such that at least one $\mathrm{Si}^{4+}$ is replaced by $\mathrm{Al}^{3+}$ and as such, exchangeable cations are non-existent due to high charge density, which imparts a non-swelling property to this clay group (Mackenzie 1975). Clinochlore belongs to the chlorite group, which is regarded as 2:1:1 type (Bleam 2017). Thus, this mineral can be rightly associated with pseudo-chlorites, which partly exhibits swelling (Mackenzie 1975). It is therefore no gainsaying that the natural soil is a clay material.

The morphology of the natural soil is shown in the grayscale image in Fig. 11a. The soil appears to be comprised of a rough texture, bearing discrete particles, which are sparsely aggregated. This suggests the presence of inter-particles void within the soil matrix, giving it a loosely packed structure. Figure $11 \mathrm{~b}$ displays the grayscale image of the lime additive. The particles of the lime are fine with the presence of disaggregated lumps, which are rounded in nature. However, on hydration, the particles rapidly dissolve and dissociate into the constituent ions $\left(\mathrm{Ca}^{2+}\right.$ and $\left.\mathrm{OH}^{-}\right)$, which are readily exchangeable within the clay pore-fluid media. The GG particles are shown in the grayscale images of Fig. 11c. The GG particles appear as fine, discrete particles, which are irregularly rounded and are easily hydroxylated to form hydro-gels.

Furthermore, the presence of active functional groups in the natural soil and additives is shown by the FTIR spectra in Table 5. There was a sharp peak at $3690 \mathrm{~cm}^{-1}$ for the natural soil that represents the stretching vibration of the $-\mathrm{OH}$ group, which can be associated with the adsorbed moisture at the DDL of the clay soil (Agunwamba et al. 2021). The peaks at 1115,1003 , and $671 \mathrm{~cm}^{-1}$ can be assigned to the asymmetric bending of the $\mathrm{Al}-\mathrm{O}$ and quartz band as a result of the significant amount of quartz mineral present in the
Fig. 11 SEM image of (a) natural soil, (b) lime, (c) GG

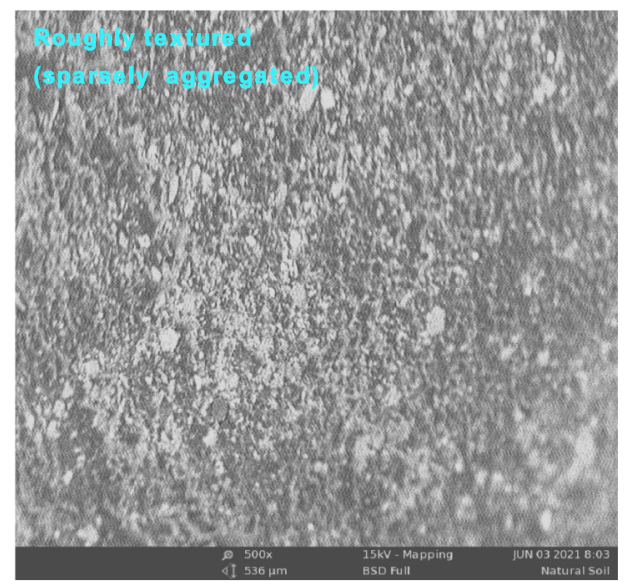

(a)

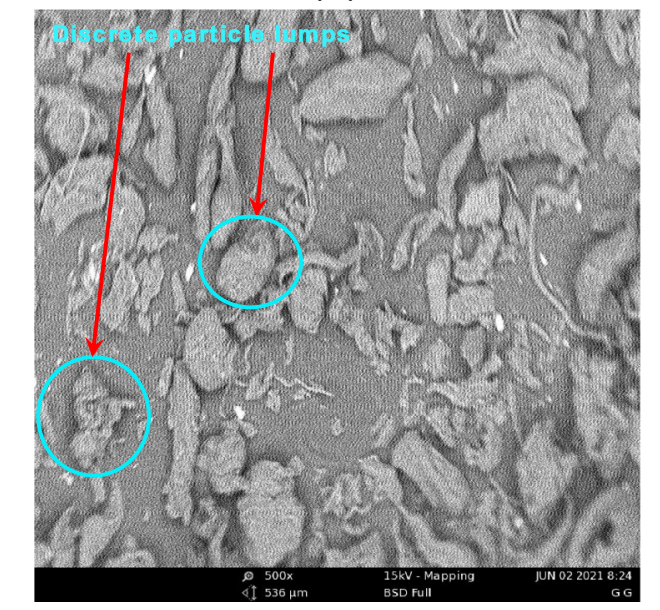

(c)

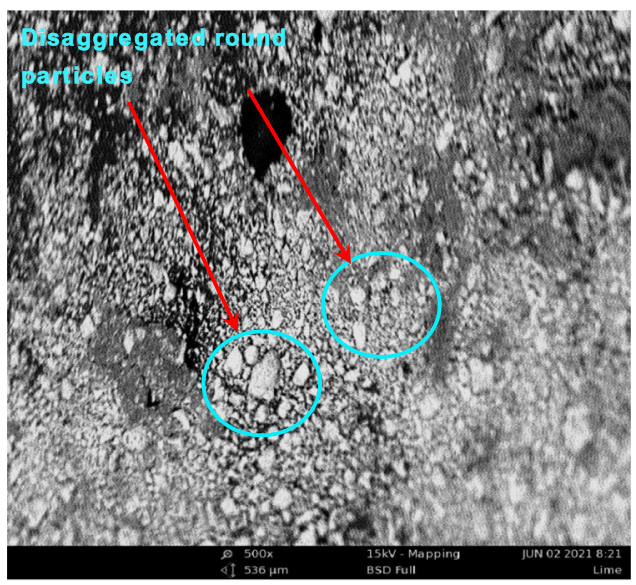

(b)

)

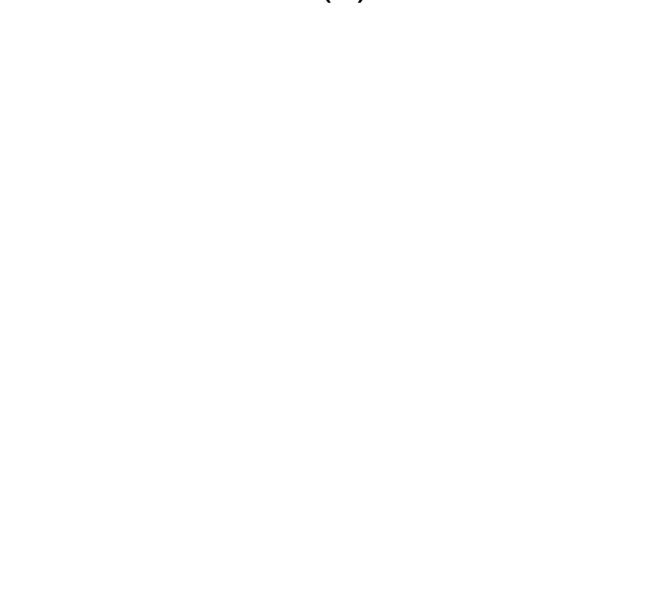


Table 5 Summary of relevant FTIR peaks for the starter materials

\begin{tabular}{lll}
\hline Material & Wave number $\left(\mathrm{cm}^{-1}\right)$ & Functional group \\
\hline Natural soil & 3690 & $-\mathrm{OH}$ \\
& 1115,1003 , and 671 & Al-O and quartz band \\
& 910 & OH deformation \\
& 753,790 & Alumina-silicates \\
Lime & $3947-1797$ & $\mathrm{H}-\mathrm{O}-\mathrm{H},-\mathrm{OH}$ \\
& 3642 & $\nu \mathrm{O}-\mathrm{H}$ \\
& 876,1523 & $\nu_{1} \mathrm{C}-\mathrm{O}$ \\
Guar gum & 3284 & $\mathrm{O}-\mathrm{H}$ \\
& 2026 and 2121,1640 & $\mathrm{O}-\mathrm{H}$ and $\mathrm{H}-\mathrm{O}-\mathrm{H}$ \\
& 1375 & $\mathrm{C}-\mathrm{H}$ \\
& 1014 & $\mathrm{C}-\mathrm{O}$ \\
\hline
\end{tabular}

soil, while the bending vibration at $910 \mathrm{~cm}^{-1}$ can be directly assigned to $\mathrm{OH}$ deformation of the double aluminum ion (Criado et al. 2005; Sharma et al. 2017). Moreover, the bending vibration at 753 and $790 \mathrm{~cm}^{-1}$ can be assigned to the vibration mode of the alumina-silicates present in the soil (Agunwamba et al. 2021). The FTIR spectrum for lime indicated very distinctive patterns. There were stretching bands between 3947 and $1797 \mathrm{~cm}^{-1}$ and they represent the presence of both weakly and strongly bonded $-\mathrm{OH}$ and $\mathrm{H}-\mathrm{O}-\mathrm{H}$ groups (Agunwamba et al. 2021; Nwonu 2021), which is reasonable because the lime used in the present study is hydrated. A very prominent peak appeared at $3642 \mathrm{~cm}^{-1}$, which can be directly linked to $\nu \mathrm{O}-\mathrm{H}$ due to the presence calcium hydroxide (Nwonu 2021). The peaks at 876 and $1523 \mathrm{~cm}^{-1}$ are directly assigned to the stretching vibration of $\nu_{1} \mathrm{C}-\mathrm{O}$ of calcium carbonate $\left(\mathrm{CaCO}_{3}\right)$ (Nwonu 2021). This is rational because the hydrated lime captures carbon dioxide $\left(\mathrm{CO}_{2}\right)$ from the ambient air to precipitate $\mathrm{CaCO}_{3}$. The FTIR spectrum for the GG is expediently interpreted based on the standard functional group table for biomolecules. A strong broad band emerged at $3284 \mathrm{~cm}^{-1}$, which is assigned to the intermolecular bond of the $\mathrm{O}-\mathrm{H}$ stretching. The peaks at 2026 and $2121 \mathrm{~cm}^{-1}$ are assigned to weakly bonded water molecules $(\mathrm{O}-\mathrm{H}, \mathrm{H}-\mathrm{O}-\mathrm{H})$, while that at $1640 \mathrm{~cm}^{-1}$ can be linked to the $\mathrm{H}-\mathrm{O}-\mathrm{H}$ weakly bonded water molecules (Nwonu 2021). The peak at $1014 \mathrm{~cm}^{-1}$ can be directly assigned to the $\mathrm{C}-\mathrm{O}$ bond of carbonyl and carboxylate in GG (Anjum et al. 2020). The peak at $1375 \mathrm{~cm}^{-1}$ can be associated with $\mathrm{C}-\mathrm{H}$ bending of aldehyde. Aldehyde is an important functional group in monosaccharides such as galactose and mannose, which make up the GG biomolecule (Sujatha and Saisree 2019; Yahia et al. 2019).

\section{Stabilized soil}

The grayscale image of the 7-day cured lime-stabilized soil at 3\% optimal lime content is shown in Fig. 12a. The soil morphology suggests that cementation has occurred since the discrete loosely packed soil structure observed for the natural soil appears to wane. The particles are therefore more closely packed, thereby reducing the inter-particles void and imparting strength gain to the soil. On further curing to 14 days, the particle aggregation becomes more conspicuous and densely packed particles are formed (Fig. 12b) due to the proliferation of cementitious compound formation resulting from chemical pozzolanic reaction within the soil matrix. This causes extra strength gain. Additional curing up to 28 days (Fig. 12c) results in a stable densely aggregated soil-additives matrix, with minimal voids prevalent. The soil at this point gives the peak values of compressive strength due to the abundance of cementitious compounds that binds the soil particles strongly, thereby forming a rigid interlock, giving it a brittle stress-strain response. The GG-stabilized soil also shows dense aggregations (Fig. 12d), due to the formation of bio-cements. The formed bio-cements bind the soil particles together, thereby forming continuous interconnected unitary soil mass which also minimizes the void spaces between adjacent interconnected particles. This imparted higher strength to the GGstabilized soil.

It is worthy of note that $0.6 \%$ GG SEM image in Fig. 12d, which was seen to give the highest strength improvement, lends credence to the threshold of the additive required. This can be ascribed to the maximum quantity of GG that formed the appropriate amount of hydro-gels needed to bind the soil particles to form a wellstructured microstructural framework for inter-particle cementation (Fig. 12d). Excessive hydroxylation due to additional GG quantity imparts an undesirable ductility behavior that diminishes strength.

In a related development, the prominent peaks of the FTIR spectra for the lime-stabilized soil are summarized in Table 6 for 7-, 14-, and 28-day curing, respectively, as well as that of the GG-stabilized soil. Lime-stabilized soil which was cured for 7 days typically exhibited peaks from 3690 to $3392 \mathrm{~cm}^{-1}$ and at $1636 \mathrm{~cm}^{-1}$ that can be attributed to the weakly and strongly bonded water molecules. The strong bonds of the $-\mathrm{OH}$ are the result of the cation exchange process in which the hydrated lime dissociates into its constituent ions and the free $-\mathrm{OH}$ molecules are in aqueous form. Additional peaks emerged at $999 \mathrm{~cm}^{-1}$ and at 787 and $749 \mathrm{~cm}^{-1}$ which can be respectively assigned to the $\nu_{\mathrm{as}} \mathrm{Si}-\mathrm{O}-\mathrm{Si}, \mathrm{Al}$ and $\nu_{\mathrm{S}} \mathrm{Si}-\mathrm{O}-\mathrm{Si}, \mathrm{Al}$ bonds of calcium alumina-silicate hydrates (CASH) due to the pozzolanic chemical reactions occurring between the hydrated lime and aluminasilicate of the soil. The FTIR band structure for the 14-day cured lime-stabilized soil exhibited similar peaks to that of the 7-day cured samples; however, a new peak emerged at $1420 \mathrm{~cm}^{-1}$, which is linked to the $\nu_{1} \mathrm{C}-\mathrm{O}$ 
Fig. 12 SEM image of (a) $3 \%$ lime-stabilized soil at 7-day curing, (b) 3\% lime-stabilized soil at 14-day curing, (c) $3 \%$ lime-stabilized soil at 28-day curing, (d) $0.6 \%$ GG-stabilized soil at 28-day curing

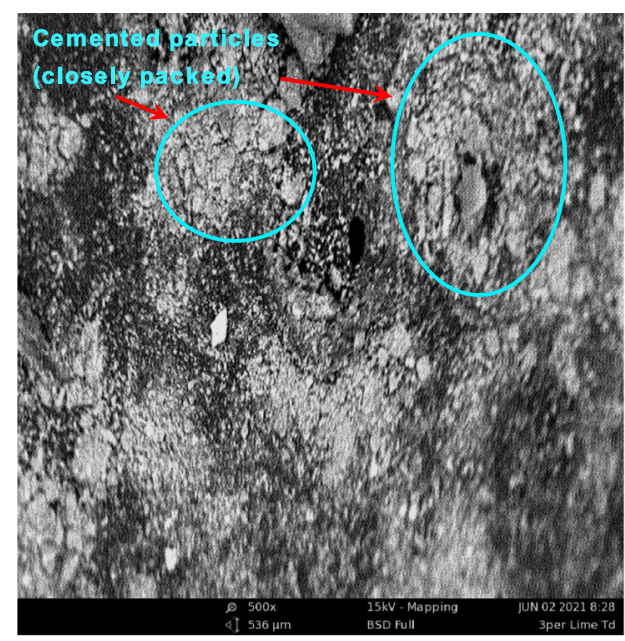

(a)

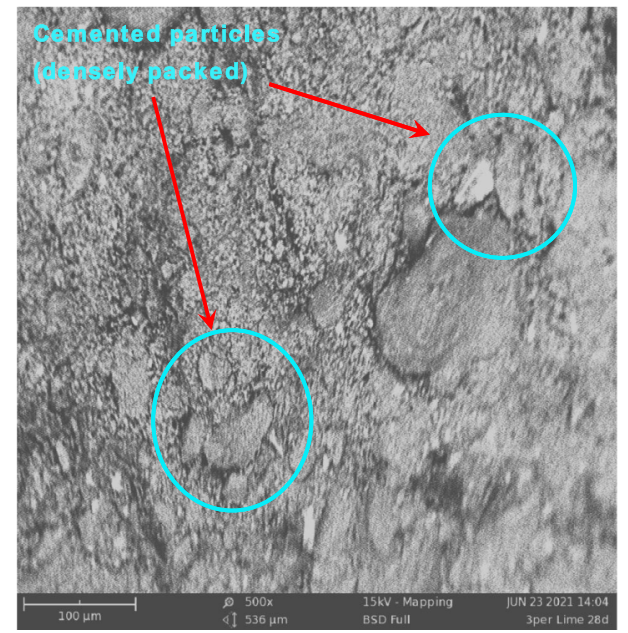

(c)

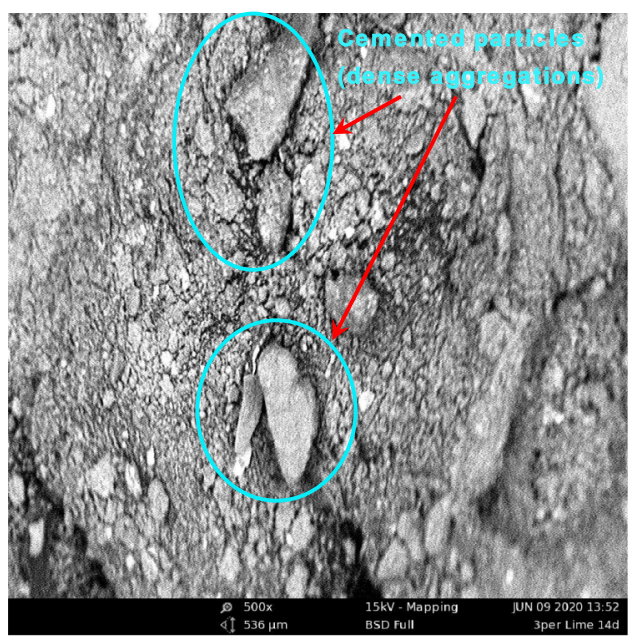

(b)

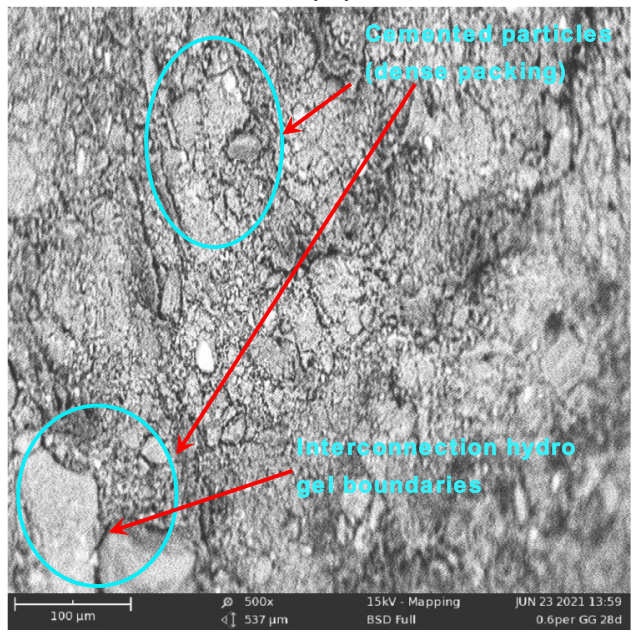

(d)

Table 6 Summary of relevant FTIR peaks and related functional groups

\begin{tabular}{lll}
\hline Designation & Wave number $\left(\mathrm{cm}^{-1}\right)$ & Functional group \\
\hline Lime-stabilized 7-day curing & $3690,3623,3392,1636$ & $-\mathrm{OH}$ and $\mathrm{H}-\mathrm{O}-\mathrm{H}$ strongly and weakly bonded water molecules \\
& 999 & $\nu_{\mathrm{as}} \mathrm{Si}-\mathrm{O}-\mathrm{Si}$, Al calcium alumina-silicate hydrates \\
Lime-stabilized 14-day curing & 787,749 & $\nu_{\mathrm{s}} \mathrm{Si}-\mathrm{O}-\mathrm{Si}$, Al calcium alumina-silicate hydrates \\
& $3690,3623,3391,1640$ & $-\mathrm{OH}$ and $\mathrm{H}-\mathrm{O}-\mathrm{H}$ strongly and weakly bonded water molecules \\
& 1420 & $\nu_{1} \mathrm{C}-\mathrm{O}$ calcium carbonate \\
Lime-stabilized 28-day curing & 999 & $\nu_{\mathrm{as}} \mathrm{Si}-\mathrm{O}-\mathrm{Si}$, Al calcium alumina-silicate hydrates \\
& 387,749 & $\nu_{\mathrm{s}} \mathrm{Si}-\mathrm{O}-\mathrm{Si}$, Al calcium alumina-silicate hydrates \\
& 1416 & $-\mathrm{OH}$ and $\mathrm{H}-\mathrm{O}-\mathrm{H}$ strongly and weakly bonded water molecules \\
GG-stabilized 28-day curing & 1006 & $\nu_{1} \mathrm{C}-\mathrm{O}$ calcium carbonate \\
& $790,753,675$ & $\nu_{\text {as }} \mathrm{Si}-\mathrm{O}-\mathrm{Si}$, Al calcium alumina-silicate hydrates \\
& 3690 & $\nu_{\mathrm{s}} \mathrm{Si}-\mathrm{O}-\mathrm{Si}$, Al calcium alumina-silicate hydrates \\
& 1002 & $\mathrm{H}-\mathrm{O}-\mathrm{H}$ strongly bonded water molecules \\
\hline
\end{tabular}


Table 7 ANOVA Table for lime-stabilized soil

\begin{tabular}{llll}
\hline Model & Source & $F$ value & $p$ value \\
\hline MLR & $\mathrm{A}$ & 6.28 & 0.041 \\
& $\mathrm{~T}$ & 193 & 0.000 \\
SPR & $\mathrm{A}$ & 48.9 & 0.000 \\
& $\mathrm{~T}$ & 14.7 & 0.009 \\
& $\mathrm{~T}^{2}$ & 35 & 0.001 \\
\hline
\end{tabular}

$F$ value represents the Fisher's statistic which is the variance ratio; $p$ value is the probability associated with the occurrence of the $F$ value

Table 8 ANOVA table for GG-stabilized soil

\begin{tabular}{llcc}
\hline Model & Source & $F$ value & $p$ value \\
\hline MLR & A & 10.1 & 0.015 \\
& T & 0.17 & 0.692 \\
SPR & A & 9.63 & 0.017 \\
& $\mathrm{~A}^{2}$ & 6.12 & 0.043 \\
\hline
\end{tabular}

$F$ value represents the Fisher's statistic which is the variance ratio; $p$ value is the probability associated with the occurrence of the $F$ value

bond of calcite. The emergence of this new peak is not unconnected with the reaction of the hydrated lime with $\mathrm{CO}_{2}$ from the ambient air to precipitate $\mathrm{CaCO}_{3}$, which imparts additional strength to the stabilized soil on dehydration. Similarly, the lime-stabilized soil cured for 28 days exhibited similar peaks with that of the 14-day cured samples with minor variations. In light of these variations, the disappearance of peaks for weakly bonded water molecules can be observed, which is due to the moisture requirement of the pozzolanic reaction with time, in which the soil-additive matrix achieved a higher level of dehydration. Moreover, an additional peak for CASH emerged at $675 \mathrm{~cm}^{-1}$ to depict the formation of more cementitious compounds. These modifications in the FTIR spectra lucidly explicate the strength gain with curing for the lime-stabilized soil. The GG-stabilized soil exhibited two notable peaks at 3690 and $1002 \mathrm{~cm}^{-1}$. The peak at $3690 \mathrm{~cm}^{-1}$ is assigned to the strongly bonded water molecules $(\mathrm{H}-\mathrm{O}-\mathrm{H})$ due to the hydroxylation of the GG to produce hydro-gels. Moreover, the peak at $1002 \mathrm{~cm}^{-1}$ is directly linked to the $\mathrm{C}-\mathrm{O}$ bonds of the carbonyl and carboxylate groups, which occur in GG (Anjum et al. 2020). These nuances provide evidence of gelation in the GG-stabilized soil.

\section{Prediction models}

Explicit relationships between the UCS, additive content, and curing time have been developed using the various regression methods previously highlighted. The model prediction equation based on MLR is shown in Eqs. 12 and 13 for lime- and GG-stabilized soils, respectively. The ANOVA for the model Eqs. 12 and 13 are respectively shown in Tables 7 and 8. Clearly, the additive content and curing time both have statistically significant effect on the UCS of the lime-stabilized soil with $p$ values $<0.05$ (Table 7). Moreover, it can be further deduced that the curing time is the more influential factor controlling the UCS based on the higher $F$ value achieved. In the GG-stabilized soil, only the additive content had a statistically significant effect on the soil UCS ( $p$ value $<0.05$ )

In another development, the relationship between the UCS, additive content, and curing time is similarly represented by the respective Eqs. 14 and 15 for lime- and GGstabilized soils based on SPR. The reported model terms are for the selected parameters based on the stepwise method. In the case of the lime-stabilized soil, all the model parameters were found to have a statistically significant effect on the UCS ( $p$ values $<0.05$ ) as shown in Table 7. Furthermore, the additive content was more influential in comparison with the curing time and its quadratic term based on the reported $F$ values. In a related development, the selected model terms for the GG-stabilized soil are based on the additive content only. Both the additive content and its quadratic term were found to have a statistically significant effect on the UCS based on the reported $p$ values which were $<0.05$ (Table 8).

The GPR model, which is an advanced technique, is applied based on the relevant algorithm, after the selection of the optimal hyper-parameters. The best result for the GPR model in the case of the lime-stabilized soil was achieved

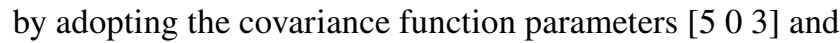
likelihood function parameter of -1 for initialization of the hyper-parameters, whereas that for the GG-stabilized soil was achieved by adopting covariance function parameters [ 3 $0.51 .5]$ and likelihood function parameter of -1 .
Table 9 Statistical performance indices for validation of the prediction models

\begin{tabular}{llllllll}
\hline Model & \multicolumn{2}{l}{ Lime-stabilized soil } & & \multicolumn{4}{l}{ GG-stabilized soil } \\
\cline { 2 - 3 } \cline { 6 - 8 } & $R^{2}$ & MAPE & RMSE & & $R^{2}$ & MAPE & RMSE \\
\hline MLR & 0.818 & 0.199 & 80.6 & & 0.334 & 0.491 & 45.9 \\
SPR & 0.806 & 0.204 & 91.5 & & 0.544 & 0.268 & 19.7 \\
GPR & 0.897 & 0.103 & 39.6 & & 0.723 & 0.176 & 12.3 \\
\hline
\end{tabular}

$M A P E$ mean absolute percentage error, $R M S E$ root mean square error, $R^{2}$ coefficient of determination 
The comparative performance of the three developed models for the UCS prediction is summarized in Table 9. The optimal model can be regarded as the one which simultaneously maximizes the $R^{2}$, while minimizing the MAPE and RMSE. A close observation of Table 9 reveals that the GPR model is the best for both the lime- and GG-stabilized soils with respective $R^{2}$ of 0.897 and 0.723 , which can be regarded to be good. The MAPE and RMSE values were also less in comparison with those of the MLR and SPR model. Apparently, the MLR and SPR models also exhibited good predictive performance for the lime-stabilized soil, based on the statistical indices in Table 9; however, their performances for the GG-stabilized soil were quite poor.

In general, for the lime-stabilized soil, the predictive performance of the three models indicates that GPR is the best, followed by the MLR and then the SPR. On the other hand, the performance of the GPR was the best, followed by the SPR and then the MLR for the GG-stabilized soil. The ability of the GPR to give a good UCS prediction for both the lime- and GG-stabilized soils is owing to its ability to adapt to a unique vicissitude for any given data since it allows the data to speak for itself and thus, serves as a robust approach for both regular and irregular data predictions.

$U C S=284.1-9.14 A+10.644 T$

$U C S=226.6-106.7 A-0.58 T$

$U C S=307-10.7 A+4.29 T+0.234 T^{2}$

$U C S=425.1-508 A+169.1 A^{2}$

\section{Conclusion}

In the present study, a comparative assessment of lime and GG for soft clay soil stabilization has been presented and a complementary approach appears to be more plausible. The improvement in the strength properties of the soil was supported microstructurally, after which predictive models were developed for the UCS prediction. The salient outcomes of the study are presented as follows:

1) Lime stabilization of the clay soil resulted in significant improvement in the consistency limits and UCS of the soil. Moreover, it was clearly shown that increase in curing period resulted to higher UCS gain. The use of 3\% lime for stabilization is recommended as the optimal additive content, considering efficacy and economy of the soil stabilization process.

2) The use of GG for the clay soil stabilization resulted in UCS gain, which peaked at $0.6 \%$ GG content. It was also discovered that improvement in UCS only occurred with up to 7-day curing, beyond which strength attenuation resulted as a result of the biodegradation of the GG by microbes in the soil. The use of GG content beyond $0.6 \%$ was found to be detrimental to the soil strength improvement and thus is not recommended.

3) Although the sole use of lime stabilization was better than that of GG, the adoption of a complementary approach using lime-GG stabilization resulted in better soil improvement than the sole use of lime stabilization. The UCS and CBR significantly improved with increase in GG content and curing for the lime-GG-stabilized soil. The formation of continuous layers of biofilms by GG imparts a self-healing effect on the brittle stress-strain response imparted to the soil by lime and as a result, the lime-GG-stabilized soil could withstand higher stresses, strains, and penetrative loads. The optimal additive content was obtained at $3 \%$ lime $+0.3 \%$ GG.

4) Assessment of the durability of the stabilized soils via SLR indicated that the lime-stabilized soil is more resistant to strength loss than the lime-GG-stabilized soils, hence, more durable. This is because during soaking, the GG particles absorb moisture continuously to swell adversely, which precludes the dehydration and crystallization of the GG hydro-gels to form the required fiber crosslinks. There is therefore the need to explore other additives, which can supplement GG to improve its durability.

5) Microstructural analysis via SEM images indicated the formation of cemented compounds in both lime- and GG-stabilized soils and showed conspicuous aggregation of stabilized soil particles to a more densely packed morphology. Moreover, the formation of cementitious compounds, particularly $\mathrm{CASH}$, was depicted in the FTIR spectra of the lime-stabilized soil, while functional groups characterizing GG were present in the GG-stabilized soils, which clarifies GG gelation.

6) Evaluation of the effect of curing on the lime-stabilized soils via SEM and FTIR indicated better aggregation, as well as the formation of additional cementitious compounds of CASH and calcite precipitate, which imparted higher strength to the soil during curing.

7) Predictive models were developed for lime- and GGstabilized soils based on MLR, SPR, and GPR. All the models developed for the lime-stabilized soil are considered to be good based on $R^{2}$ values generally above 0.8 and low error values (MAPE and RMSE). However, only the GPR model was found to be good for predicting the UCS of the GG-stabilized soil with $R^{2}$ of 0.723 . Overall, the GPR model was found to be superior to MLR and SPR models for delineating the relationship between the UCS, additive content, and curing time. 
Acknowledgements The authors wish to acknowledge the immense contributions of Uwemedidare Akpan, Ikenna Urama, and Levi Ugwu in the execution of this study. The second author further appreciates the UK Foreign Commonwealth and Development Office (FCDO) and the University of the West of Scotland for their respective contribution towards his career progression.

\section{Declarations}

Conflict of interest The authors declare no competing interests.

Open Access This article is licensed under a Creative Commons Attribution 4.0 International License, which permits use, sharing, adaptation, distribution and reproduction in any medium or format, as long as you give appropriate credit to the original author(s) and the source, provide a link to the Creative Commons licence, and indicate if changes were made. The images or other third party material in this article are included in the article's Creative Commons licence, unless indicated otherwise in a credit line to the material. If material is not included in the article's Creative Commons licence and your intended use is not permitted by statutory regulation or exceeds the permitted use, you will need to obtain permission directly from the copyright holder. To view a copy of this licence, visit http://creativecommons.org/licenses/by/4.0/.

\section{References}

Acharya R, Pedaria A, Bheemasetti TV, Puppala AJ (2017) Assessment of guar gum biopolymer treatment toward mitigation of desiccation cracking on slopes built with expansive soils. Transp Res Rec 2657:78-88

Agunwamba JC, Onyia ME, Nwonu DC (2021) Development of expansive soil geopolymer binders for use in waste containment facility. Innov Infrastruct Solut. https://doi.org/10.1007/ s41062-020-00400-0

Al-taie A, Disfani M, Evans R, Arulrajah A, Horpibulsuk S (2016) Impact of curing on behaviuor of basaltic expansive clay. Road Mater Pavement Des. https://doi.org/10.1080/14680629.2016. 1267660

Anjum F, Gul S, Khan MI, Khan MA (2020) Efficient synthesis of palladium nanoparticles using guar gum as stabilizer and their applications as catalyst in reduction reactions and degradation of azo dyes. Green Process Synth 9:63-76

Ayeldeen M, Negm A, El-Sawwaf M, Kitazume M (2017) Enhancing mechanical behaviors of collapsible soil using two biopolymers. J Rock Mech Geotech Eng 9:329-339

Bagriacik B, Mahmutluoglu B (2021) Model experiments on coarsegrained soils treated with xanthan gum biopolymer. Arab J Geosci. https://doi.org/10.1007/s12517-021-08134-8

Bleam W (2017) Clay mineralogy and chemistry. In Soil and environmental chemistry. Academic Press. pp. 87-146. https://doi.org/ 10.1016/C2015-0-01022-X

Chakraborty S, Nair S (2020) Impact of curing time on moistureinduced damage in lime-treated soils. Int J Pavement Eng 21:215-227. https://doi.org/10.1080/10298436.2018.1453068

Chang I, Lee M, Tran AP, Lee S, Kwon Y, Im J, Cho G (2020) Review of biopolymer-based soil treatment (BPST) technology in geotechnical engineering practices. Transp Geotechnics 24:100385. https://doi.org/10.1016/j.trgeo.2020.100385

Chen R, Zhang L, Budhu M (2013) Biopolymer stabilization of mine tailings. J Geotech Geoenviron Eng 139:1802-1807
Criado M, Palomo A, Fernandez-Jimenez A (2005) Alkai activation of fly ashes. Part 1: Effect of curing conditions on the carbonation of the reaction products. Fuel 84:2048-2054

Ebden M (2008) Gaussian proesses for regression: a quick introduction.Academia. https://www.academia.edu/35631318/Gaussian_ Processes_for_Regression_A_Quick_Introduction. Accessed 13 Nov 2021

Etim RK, Eberemu AO, Osinubi KJ (2017) Stabilization of black cotton soil with lime and iron ore tailings admixture. Transp Geotech 10:85-95. https://doi.org/10.1016/j.trgeo.2017.01.002

Eujine GN, Chandrakaran S, Sankar N (2017) Influence of enzymatic lime on clay mineral behavior. Arab J Geosci 10:454. https://doi. org/10.1007/s12517-017-3238-z

Fatehi H, Ong DEL, Yu J, Chang I (2021) Biopolymers as green binders for soil improvement in geotechnical application: a review. Geosciences 11:1-39. https://doi.org/10.3390/geosciences1107 0291

Ikeagwuani CC, Nwonu DC (2019) Emerging trends in expansive soil stabilisation: A review. J Rock Mech Geotech Eng 11:423440. https://doi.org/10.1016/j.jrmge.2018.08.013

Ikeagwuani CC, Nwonu DC (2021) Infuence of dilatancy behavior on the numerical modeling and prediction of slope stability of stabilized expansive soil slope. Arab J Sci Eng. https://doi.org/ 10.1007/s13369-021-05764-8

Ikeagwuani CC, Obeta IN, Agunwamba JC (2019) Stabilization of black cotton soil subgrade using sawdust ash and lime. Soils Found 59:162-175. https://doi.org/10.1016/j.sandf.2018.10.004

Jong SC, Ong DEL, Oh E (2021) State-of-the-art review of geotechnical-driven artificial intelligence techniques in underground soil-structure interaction. Tunn Undergr Space Technol. https:// doi.org/10.1016/j.tust.2021.103946

Kampala A, Jitsangiam P, Pimraksa K, Chindaprasirt P (2020) An investigation of sulfate effects on compaction characteristics and strength development of cement-treated sulfate bearing clay subgrade. Road Mater Pavement Des. https://doi.org/10.1080/ 14680629.2020 .1753564

Mackenzie RC (1975) The classification of soil silicates and oxides. Soil components. Springer-Verlag, New York, pp 1-25

Moghal AB, Ashfaq M, Al-Obaid AK, Abbas MF, Al-Mahbashi AM, Shakar AA (2020) Compaction delay and its effect on the geotechnical properties of lime treated semi-arid soils. Road Mater Pavement Des. https://doi.org/10.1080/14680629.2020.1784256

Mudgil D, Barak S, Khatkar BS (2014) Guar gum: processing, properties and food applications - a review. J Food Sci Technol 51:409-418. https://doi.org/10.1007/s13197-011-0522-x

Mugada S, Booth SJ, Hughes PN, Augarde CE, Perlot C, Bruno AW, Gallipoli D (2017) Mechanical properties of biopolymer-stabilised soil-based construction materials. Geotech Lett 7:309-314

Murthy VN (2002) Principles and Practices of Soil Mechanics and Foundation Engineering. Marcel Decker INC, New York

Nigerian General Specification (1997) Nigerian general specification for roads and bridges. Federal Ministry of Works and Housing, Abuja

Nwonu DC (2021) Exploring soil geopolymer technology in soft ground improvement: a brief excursion. Arab J Geosci. https:// doi.org/10.1007/s12517-021-06832-x

Nwonu DC, Ikeagwuani CC (2021a) Evaluating the effect of agrobased admixture on lime-treated expansive soil for subgrade material. Int J Pavement Eng. https://doi.org/10.1080/10298 436.2019.1703979

Nwonu DC, Ikeagwuani CC (2021b) Microdust effect on the physical condition and microstructure of tropical black clay. Int $\mathrm{J}$ Pavement Res Technol 14:73-84. https://doi.org/10.1007/ s42947-020-0004-5 
Rasmussen C, Williams C (2006) Gaussian process for machine learning. MIT Press, Cambridge

Rosone M, Celauro C, Ferrari A (2020) Microstructure and shear strength evolution of a lime-treated clay for use in road construction. Int J Pavement Eng 21:1147-1158

Sharma LK, Sirdesai NN, Sharma KM, Singh TN (2017) Experimental study to examine the independent roles of lime and cement on the stabilization of a mountain soil. Appl Clay Sci 152:183-195

Sivia D, Skilling J (2006) Data analysis: a Bayesian tutorial. Oxford University Press, New York

Smitha S, Rangaswamy K (2021) Experimental study on unconfined compressive and cyclic triaxial test behavior of aga biopolymer-treated silty sand. Arab J Geosci. https://doi.org/10.1007/ s12517-021-06955-1

Soldo A, Miletic M, Auad M (2020) Biopoymers as a sustainable solution for the enhancement of soil mechanical properties. Sci Rep. https://doi.org/10.1038/s41598-019-57135-x
Soltani A, Deng A, Taheri A (2018) Swell-compresion characteristics of a fibre-reinforced expansive soil. Geotext Geomembr 46:183-189

Sujatha ER, Saisree S (2019) Geotechnical behaviour of guar gumtreated soil. Soils Found 59:2155-2166

Sujatha ER, Saisree S, Kumar SA (2020) Impact of hydration and gelling properties of guar gum on the mechanism of soil modification. Arab J Geosci. https://doi.org/10.1007/ s12517-020-06258-x

Vishweshwaran M, Sujatha ER (2021) Experimental investigation and numerical modeling of a cross-linked biopolymer stabilized soil. Arab J Geosci. https://doi.org/10.1007/s12517-021-08260-3

Viswanath SM, Booth SJ, Hughes PN, Augarde CE, Perlot C, Bruno AW, Gallipolli D (2017) Mechanical properties of biopoymerstabilised soil-based construction materials. Geotech Lett 7:1-18

Yahia EM, Carrillio-Lopez A, Bello-Perez LA (2019) Carbohydrates. Postharvest physiology and biochemistry of fruits and vegetables. Woodhead Publishing, Cambridge, pp 175-205 